\title{
Assessment of quartz grain growth and the application of the wattmeter to predict recrystallized grain sizes
}

Leif Tokle ${ }^{1,2}$ and Greg Hirth ${ }^{2}$

1. Structural Geology and Tectonics Group, Geological Institute, Department of Earth Sciences, ETH Zurich, Sonneggstrasse 5, 8092, Zurich, Switzerland

2.Department of Earth, Environmental and Planetary Sciences, Brown University, Providence, RI 02912.

Corresponding author: leif.tokle@erdw.ethz.ch

Key points

1. We find different recrystallized grain size versus stress relationships in samples with prism $<\mathrm{a}>$ and basal $<\mathrm{a}>\mathrm{c}$-axis fabrics

2. We reformulate a new grain growth law for wet quartzite

3. We find no temperature or water fugacity dependence on the recrystallized grain size within error, consistent with experimental observations 


\begin{abstract}
We investigated relationships between the recrystallized grain size and stress in experimentally deformed water-added quartz aggregates. For stresses $\geq 100 \mathrm{MPa}$ there is a variation in the measured recrystallized grain size for a given stress. We found this variation correlates with a change in the c-axis fabric in general shear experiments, where samples with larger recrystallized grain sizes for a given stress have dominantly prism $<\mathrm{a}>\mathrm{c}$-axis fabrics and samples with smaller recrystallized grain sizes for a given stress have dominantly basal $<a>c$-axis fabrics. The dislocation creep flow law also changes at conditions where these two c-axis fabrics form (Tokle et al., 2019). Using the wattmeter model (Austin and Evans, 2007), we quantify piezometric relationships for samples that develop prism $<\mathrm{a}>$ and basal $<\mathrm{a}>\mathrm{c}-$ axis fabrics, respectively. The wattmeter model is sensitive to grain growth kinetics; we formulated a new grain growth law for quartz based on reanalysis of microstructures in samples from previous work (Tullis and Yund, 1982). The activation enthalpies and water fugacity exponents for our grain growth law and dislocation creep flow laws are the same within error, suggesting the recrystallized grain size versus stress relationships are nearly independent of temperature and water fugacity, consistent with laboratory observations. The wattmeters successfully predict the recrystallized grain size versus stress relationships of all water-added experimental quartz samples. Our results provide support for the use and extrapolation of the wattmeter model to both experimental and geologic conditions to investigate the stress state and grain size evolution of quartz rich rocks.
\end{abstract}

\title{
Plain Language Summary
}

Stress is a fundamental rheological parameter in understanding how rocks deform; however, stress is hard to quantify in rocks that flow rather than fracture at geologic conditions. The relationship between the recrystallized grain size and stress is established through rock deformation experiments where both the stress and grain size can be measured. Therefore, the stress can be estimated in naturally deformed rocks by measuring the recrystallized grain size and applying the experimentally calibrated relationship. Here we show new evidence for different recrystallized grain size versus stress relationships in quartz, and that these different relationships correlate with the crystallographic orientations of grains in samples deformed in the shear geometry. To quantify these new observations, we use the wattmeter model, which models the recrystallized grain size of a deforming aggregate based on the balance between the rates of grain growth and grain size reduction, to predict the quartz recrystallized grain size. This model is sensitive to grain growth kinetics; therefore, we formulated a new grain 
growth law for quartz. Our calibrated wattmeters predict the recrystallized grain size versus stress relationships in experimentally deformed wet quartzite samples. Our wattmeter model can therefore be used to estimate stress magnitudes in naturally deformed quartz-rich rocks.

\section{Introduction}

Due to the abundance of quartz in the continental crust, quartz rheology is fundamental to our understanding of many geodynamic processes. Grain size is an important parameter in the rheology of many materials, including quartz. In addition, a practical technique to infer stress magnitudes in the continental crust is the piezometric relationship between recrystallized grain size and stress, expressed as:

$d=A_{o} \sigma^{-k}$

where $d$ is recrystallized grain size, $\sigma$ is differential stress, and $A_{o}$ and $k$ are constants (Twiss, 1977; Stipp and Tullis, 2003). The most widely applied recrystallized grain size piezometer for quartz was empirically developed based on recrystallized grain size measurements from 12 deformation experiments conducted on " $a s$-is" quartzite (i.e., without pre-drying or adding water) in axial compression at temperatures between $800-1100^{\circ} \mathrm{C}$, where $A_{o}$ and $k$ are 3631 and 1.26, respectively (Stipp and Tullis, 2003); we refer to this relationship as the S\&T piezometer. Stipp and Tullis (2003) quantified a second piezometric relationship at higher stresses (> $350 \mathrm{MPa})$ and smaller grain sizes $(\lesssim 2 \mu \mathrm{m})$ based on axial compression experiments of as-is novaculite conducted by Bishop (1996). Furthermore, Stipp et al. (2006) conducted axial compression experiments on water-added and pre-dried quartz samples, showing that over the range of measured stresses and grain sizes there is no difference in the piezometric relationship for water-added, as-is, or pre-dried quartz samples. Kidder et al. (2016) conducted deformation experiments on water-added quartzite aggregates in axial compression and showed similar results to those produced by Stipp and Tullis (2003) and Bishop (1996).

Analyses of samples deformed in general shear suggest that the recrystallized grain size piezometer for quartz is not as simple as presented in Stipp and Tullis (2003) and Twiss (1977). Heilbronner and Kilian (2017) reanalyzed as-is and water-added samples from Heilbronner and Tullis $(2002 ; 2006)$ deformed in the general shear geometry and demonstrated that the general shear samples plot at larger grain sizes than the axial compression experiments for a given equivalent stress (Figure 1a). Richter et al. (2018) deformed water-added quartz aggregates in the general shear geometry at a wider range of experimental conditions than those analyzed by Heilbronner and Kilian (2017) and found that 
some samples fit the S\&T piezometer while others fit the relationship determined by Heilbronner and Kilian (2017) (Figure 1a). Soleymani et al. (2020) deformed water-added silica-gel origin samples in the general shear geometry and found all of their samples fit the S\&T piezometer.

The recrystallized grain size versus stress relationship has important implications for our understanding of stress in the continental crust. For example, one could fit the compiled data set in Figure 1, suggesting that the recrystallized grain size is not as strongly dependent on stress as indicated by the S\&T piezometer. In contrast, we illustrate that the variability in recrystallized grain size versus stress relationship can be reconciled by applying the wattmeter (Austin and Evans, 2007) and accounting for differences in quartzite flow laws at the experimental conditions. We analyze recrystallized grain sizes and mechanical data from five studies on experimentally deformed wet quartzites (Figure 1c,d). We develop two wattmeters for quartz, utilizing the two flow laws determined by Tokle et al. (2019). As part of our analysis, we reformulate a grain growth law for quartz aggregates, which is a fundamental component of the wattmeter model. Using our newly formulated wattmeters, we extrapolate to crustal conditions to evaluate stress estimates based on published grain size and c-axis fabric data. 

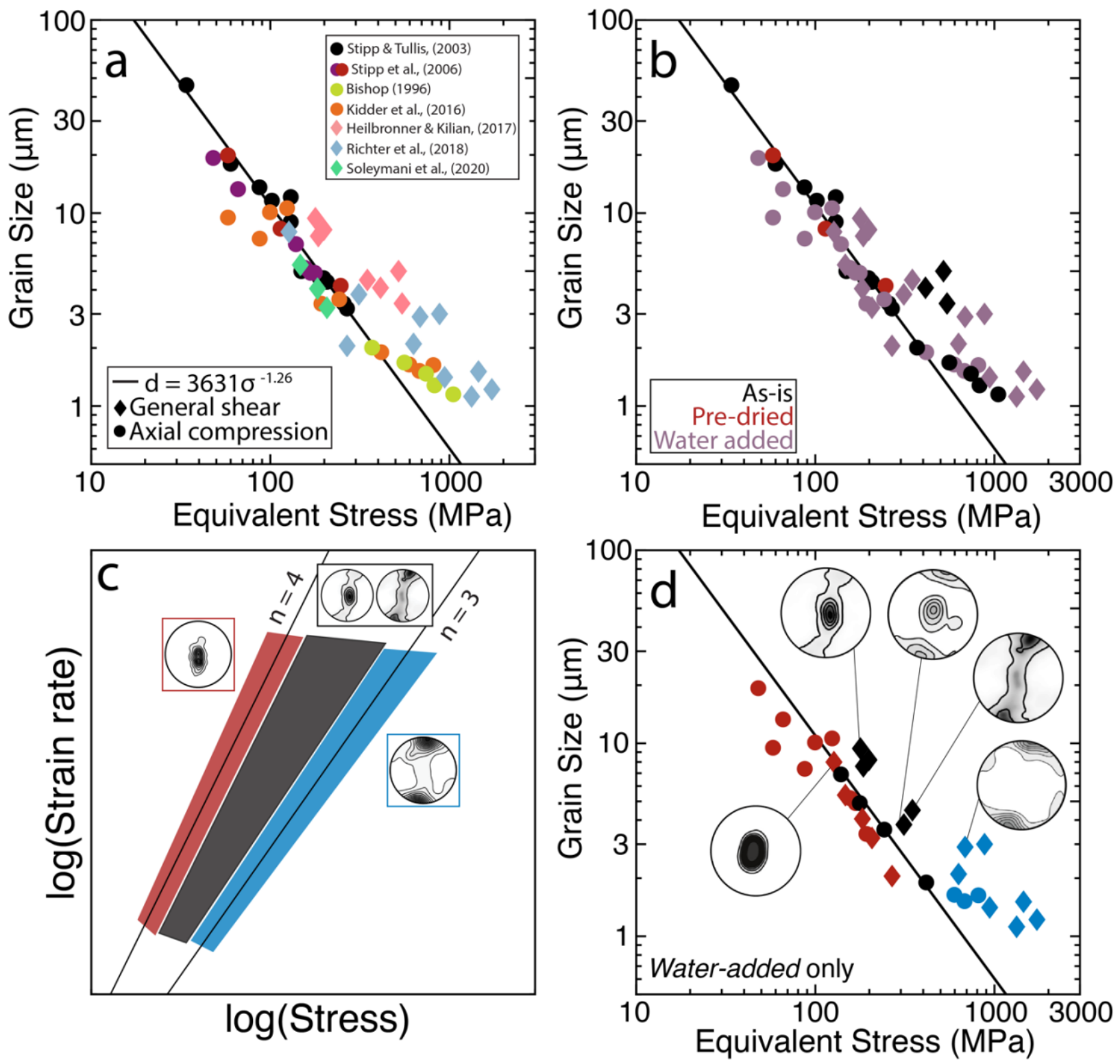

Figure 1. Plots of log equivalent stress versus log grain size color-coded by a) study and b) whether the starting material was pre-dried, as-is, or water-added.c) plot of log stress versus log strain rate showing the two flow laws derived by Tokle et al. (2019) and the transitional region color-coded, red, blue, and black respectively. d) plot of log equivalent stress versus log grain size for the water-added samples color-coded by their c-axis fabric and/or where the sample plots in stress versus strain rate space. In c) and d) the pole figures are oriented with the shear plane in the E-W orientation with a dextral sense of shear.

\section{Experimental data}

We analyze recrystallized grain sizes and mechanical data from five different experimental studies; two employed an axial compression deformation geometry (Stipp et al., 2006; Kidder et al. 2016) and three employed the general shear geometry (Heilbronner and Kilian, 2017; Richter et al. 2018; Soleymani et al. 2020). In all five studies, experiments were conducted in a solid-medium Griggs apparatus using either an all-salt or molten-salt assembly. To be 
consistent with wet dislocation creep flow laws and wet grain growth laws, the wattmeter is calibrated with recrystallized grain size versus stress data from water-added $\left(\sim 0.2 \mathrm{wt} . \% \mathrm{H}_{2} \mathrm{O}\right)$ samples. All of the water-added deformation experiments were conducted at temperatures between 700 and $1000^{\circ} \mathrm{C}$ and at confining pressures ranging from 1.06 to $1.58 \mathrm{GPa}$. In section 5.3, we also compare the wattmeter model, calibrated with water-added samples, with as-is and pre-dried experiments conducted at temperatures of $800-1100^{\circ} \mathrm{C}$ and a pressure of 1.5 GPa (Stipp and Tullis, 2003; Stipp et al., 2006). For general shear experiments, shear stresses and shear strain rates were converted to equivalent stresses ( $\sigma_{\text {eqv }}=\sqrt{3} \tau$, where $\tau$ is shear stress) and equivalent strain rates $\left(\dot{\varepsilon}_{e q v}=\frac{\dot{\gamma}}{\sqrt{3}}\right.$, where $\dot{\gamma}$ is shear strain) (Paterson and Olgaard, 2000). We use the mechanical data reported in the respective papers, and therefore do not apply the calibration for the Griggs apparatus developed by Holyoke and Kronenberg (2010) (see section 6.1 from Tokle et al. 2019). Some figures illustrating the role of stress state are presented in the supplemental information (Figures S1, S2).

All of the recrystallized grain sizes from water-added samples analyzed in this study were measured using either electron backscatter diffraction (EBSD) or computer-integrated polarized (CIP) microscopy (Panozzo Heilbronner and Pauli, 1993; Heilbronner and Tullis, 2006). We use the root mean square (RMS) diameter of the 2D grain size; this choice provides us with the largest dataset (33 experimental datapoints). Cross et al. (2017) reanalyzed 9 of the 21 experiments from Stipp and Tullis (2003) and Stipp et al. (2006) and showed that the RMS grain sizes determined from EBSD and CIP were the same within error over the stress range of 48 to $177 \mathrm{MPa}$ - with the exception of sample W1143 (see Figure 4a in Cross et al. 2017). Thus, we are confident that our compiled dataset is not systematically biased by including data acquired by the different techniques. We recognize that, by definition, the RMS of the grain diameter is considered an upper estimate of the $2 \mathrm{D}$ grain size (Heilbronner and Kilian, 2017; Cross et al. 2017); in section 5.5 we discuss how using the arithmetic mean grain diameter affects our analysis. All of the recrystallized grain size versus stress data used in this study are listed in supplementary Table S1.

\subsection{Deviation in the recrystallized grain size versus stress relationship}

The recrystallized grain size versus stress data show an increasing range of deviation from the S\&T piezometer at stresses greater than $\sim 100 \mathrm{MPa}$, with select samples showing a larger grain size for a given stress (Figure 1). These deviations are apparent for both water-added and $a s$-is experiments, indicating that the scatter does not reflect a systematic effect of water 
content (Figure 1b). Figure 1 also shows that deviation from the piezometer cannot be systematically explained by differences in deformation geometry.

The deviation of recrystallized grain size versus stress data from the S\&T piezometer correlates with differences in the crystallographic preferred orientation (CPO). As shown in Figures $1 \mathrm{c}$ and 1d, samples that develop prism <a> c-axis fabrics plot on, or at smaller grain sizes, than the S\&T piezometer, while samples that develop basal $<a>c$-axis fabrics plot at larger grain sizes than the $\mathrm{S} \& \mathrm{~T}$ piezometer. Samples that exhibit a mixture of basal $<\mathrm{a}>$, prism $<\mathrm{a}>$, and rhomb $<\mathrm{a}>\mathrm{c}$-axis fabrics plot on, or at larger grain sizes than the S\&T piezometer.

The concomitant switch in the c-axis fabric and recrystallized grain size versus stress relationships is analogous to the observation of changes in quartzite flow laws at the same deformation conditions. Tokle et al. (2019) show a concomitant switch in the c-axis fabric and the stress exponent, where the stress exponent changes from $n=4$ at high temperature/low stresses to $n=3$ at low temperature/high stresses; these changes correlate with the transition from prism $<a>c$-axis fabrics at high temperature/low stresses to basal $<a>c$-axis fabrics at low temperature/high stresses (Figures 1c and 1d). In Figure 1, samples for which c-axis fabrics were not reported are color-coded based on whether they plot on the $n=4$ or the $n=3$ flow law defined by Tokle et al. (2019), or in the transitional regime between the two flow laws (Figure 1c). These trends suggest that the slope of the recrystallized grain size versus stress relationship correlates with a change in the stress exponent; this trend, which is predicted for the wattmeter (see below; Austin and Evans, 2007), provided part of the motivation for our analysis.

The S\&T piezometer (and the one modified by Cross et al., 2017) were calibrated from samples deformed at relatively low flow stresses ( 30 - $300 \mathrm{MPa})$. Both studies also acknowledge that at larger stresses and smaller grain sizes the recrystallized grain size versus stress relationship changes based on the experimental observations of Bishop (1996). As such, inspection of Figure 1 indicates that the piezometric relationships are primarily calibrated using samples where prism $<\mathrm{a}>\mathrm{c}$-axis fabrics develop in general shear experiments. The S\&T piezometer (as well as the Cross et al., 2017 piezometer) does not fit the majority of data from samples that develop either mixed c-axis fabrics or dominantly basal <a>c-axis fabrics (Figure 1d). Tokle et al. (2019) highlighted that the change in c-axis fabric observed in experimental samples is also observed in natural quartzites deformed at lower temperatures $\left(\leq \sim 400^{\circ} \mathrm{C}\right)$, suggesting that the current recrystallized grain size 
piezometers may not accurately estimate paleo-stress for samples deformed at mid-crustal temperatures.

\section{The Wattmeter}

To investigate the origin for different recrystallized grain size versus stress relationships presented in Figure 1, we apply the wattmeter model (Austin and Evans, 2007, 2009). The wattmeter is a relatively simple grain size evolution model that is practical to apply. The wattmeter is defined as a scaling relationship representing a dynamic balance between the rates of grain growth and grain size reduction, where the grain size evolution rate is expressed as (Austin and Evans, 2007, 2009):

$$
\dot{d}=K_{g} e^{\left(\frac{-Q_{g}}{R T}\right)} p^{-1} d^{1-p}-\frac{\beta \lambda \sigma \dot{\varepsilon} d^{2}}{\pi \gamma}
$$

The scaling factor $\lambda$ is defined as the fraction of total energy input during dislocation creep $(\sigma \dot{\varepsilon})$ that is not dissipated as heat, which is available to change the internal energy through the creation of crystal defects (Austin and Evans, 2007; 2009). See Table 1 for definition of all symbols and their values. Setting the grain size evolution rate to zero $(\dot{d}=0)$, the steady state grain size is defined as:

$d^{1+p}=\frac{K_{g} e^{\left(\frac{-Q_{g}}{R T}\right)} p^{-1} \pi \gamma}{\beta \lambda \sigma \dot{\varepsilon}}$,

and by inserting the dislocation creep flow law into the strain rate term and expanding the $k g$ term from the grain growth law into equation 3, the steady state grain size becomes:

$d=C \sigma^{-k^{\prime}} f_{H_{2} O}^{r^{\prime}} e^{\left(\frac{Q^{\prime}}{R T}\right)}$

where $C=\left(\frac{A_{g} \pi \gamma}{A \beta \lambda p}\right)^{\frac{1}{p+1}}, k^{\prime}=\frac{n+1}{p+1}, r^{\prime}=\frac{r_{g}-r}{p+1}$ and $Q^{\prime}=\frac{Q_{g}-Q}{p+1}$. Therefore, with well-established flow laws and grain growth laws, the wattmeter model can be used to investigate recrystallized grain size versus stress relationships.

The steady state grain size defined by equation 4 provides several useful relationships not represented in the classic recrystallized grain size piezometers, where $A_{o}$ and $k$ in 
equation 1 are empirically fit (Stipp and Tullis, 2003) or theoretically estimated (Twiss, 1977). Equation 4 illustrates that the slope, $k$, of the recrystallized grain size versus stress relationship is related to the stress exponent $(n)$ for dislocation creep and the grain growth exponent $(p)$ from the grain growth law, which indicates that changing $n$ or $p$ will change the slope of the recrystallized grain size versus stress relationship. This effect is consistent with our observation illustrated in Figure 1d; assuming the grain growth exponent is constant, the slope of the recrystallized grain size versus stress relationship will be steeper for samples that define the $n=4$ flow law than the $n=3$ flow law. Equation 4 also shows that the steady state grain size for a given stress can depend on temperature and water fugacity if $Q_{g} \neq Q$ and/or $r_{g}$ $\neq r$, respectively (c.f. Austin and Evans, 2007; deBresser et al., 1998, 2001). From this context, the observation that the quartz grain size piezometers do not show an obvious influence of temperature or water content suggests that $Q_{g} \approx Q$ and $r_{g} \approx r$, respectively (Stipp and Tullis, 2003; Stipp et al. 2006; Kidder et al. 2016).

\section{Table 1. List of Symbols and Descriptions}

$A_{o} \quad$ preexponential constant for recrystallized grain size piezometer in equ. 1

$k \quad$ stress exponent for recrystallized grain size piezometer in equ. 1

$\dot{d} \quad$ Grain size evolution rate $\left[\mu \mathrm{m} \mathrm{s}^{-1}\right]$

$Q_{g} \quad$ activation enthalpy for grain growth $[\mathrm{kJ} / \mathrm{mol}]$

$k_{g} \quad$ Grain growth preexponential $\left[\mu \mathrm{m}^{\mathrm{p}} \mathrm{s}^{-1}\right]$

$A_{g} \quad$ preexponential constant for grain growth

$r_{g} \quad$ water fugacity exponent for grain growth

$V_{g} \quad$ activation volume for grain growth $\left[\mathrm{cm}^{3} / \mathrm{mol}\right]$

$t$ time

$d \quad$ grain size after time $t[\mu \mathrm{m}]$

$d_{o} \quad$ grain size at $t=0[\mu \mathrm{m}]$

$p \quad$ grain growth exponent

$\lambda \quad$ Proportion of the energy associated with dislocation creep stored in the microstructure

$\beta \quad$ Fraction of the total mechanical work rate accommodated by dislocation creep

$\pi \quad$ geometric constant [3.14]

$\gamma \quad$ Grain boundary energy $\left[1 \mathrm{~J} \mathrm{~m}^{-2}\right]$

$\dot{\varepsilon} \quad$ Strain rate $\left[\mathrm{s}^{-1}\right]$

$A \quad$ Material parameter for creep

$\sigma \quad$ Differential Stress [MPa]

$n \quad$ Stress Exponent

$f_{\mathrm{H}_{2} \mathrm{O}} \quad$ water fugacity [MPa]

$r \quad$ water fugacity exponent for creep

$Q \quad$ activation enthalpy for creep mechanism

$V \quad$ activation volume $\left[\mathrm{cm}^{3} / \mathrm{mol}\right]$

$R \quad$ Gas constant $\left[8.314 \mathrm{~J} \mathrm{~K}^{-1} \mathrm{~mol}^{-1}\right.$ ]

$T$ Temperature [K] 


\section{Reanalysis of a wet quartz grain growth law}

Improving our understanding of grain growth kinetics for quartz will improve our ability to model quartz grain size evolution. The most widely applied grain growth law for wet quartz was derived by Wightman et al. (2006) based on the grain growth experiments conducted by Tullis and Yund (1982). Wightman et al. (2006) determined their grain growth law using all of the experimental data presented in Tullis and Yund (1982). However, Tullis and Yund (1982) showed that grain growth in all of the jasper experiments was influenced by the presence of iron oxides (see Figure 2 in Tullis and Yund, 1982). The presence of secondary phases, even at small volume fractions can significantly impact grain growth kinetics (e.g. Olgaard and Evans, 1986,1988; Evans et al. 2001).
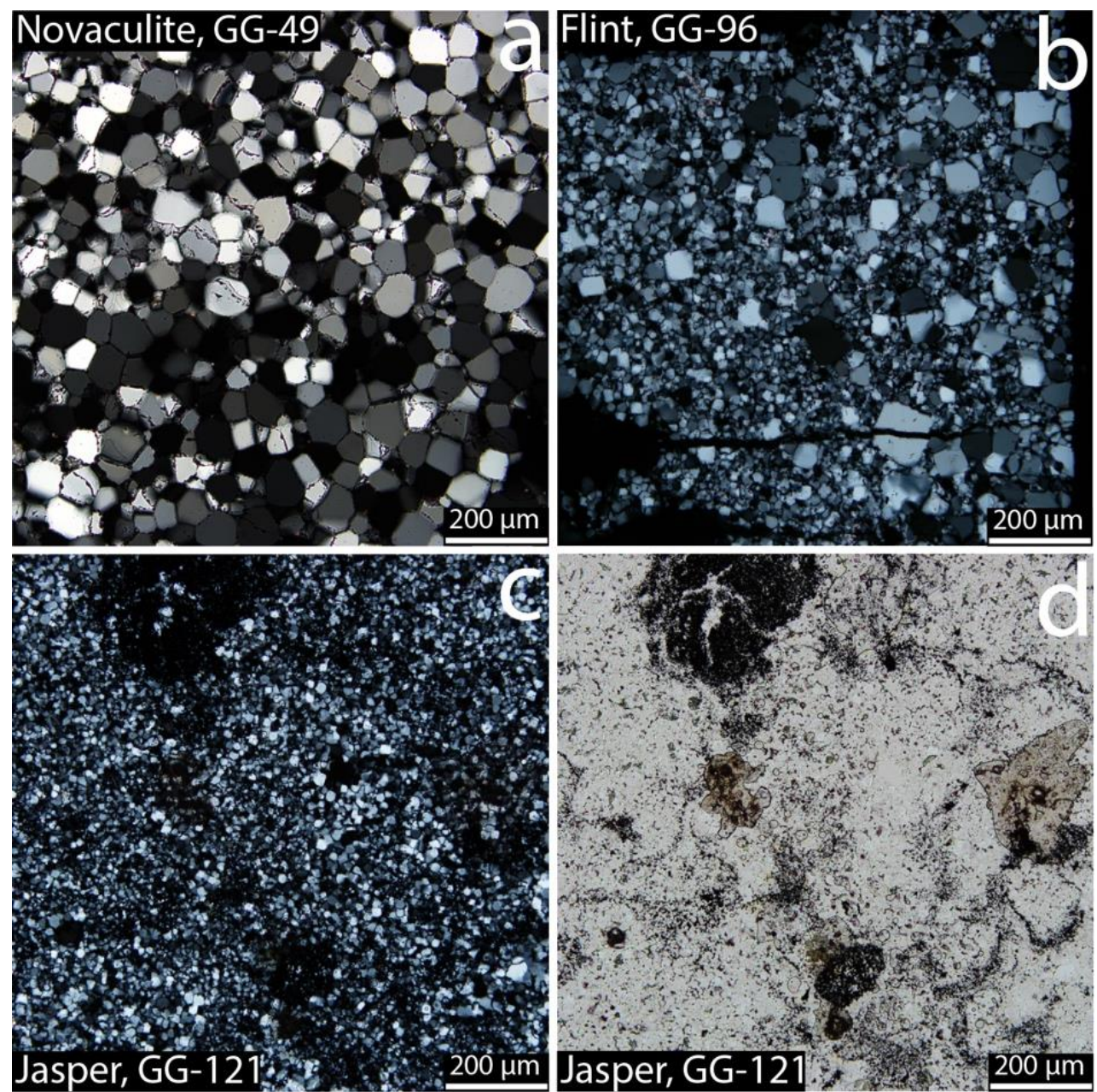

Figure 2. Cross-polarized and plane light photomicrographs of quartz grain growth experiments from Tullis and Yund (1982) showing a) normal grain growth, b) abnormal grain growth and the presence of oxides as secondary phases c) in cross-polarized and d) plane light. The oxides are the black mineral visible in the plane light micrograph. 

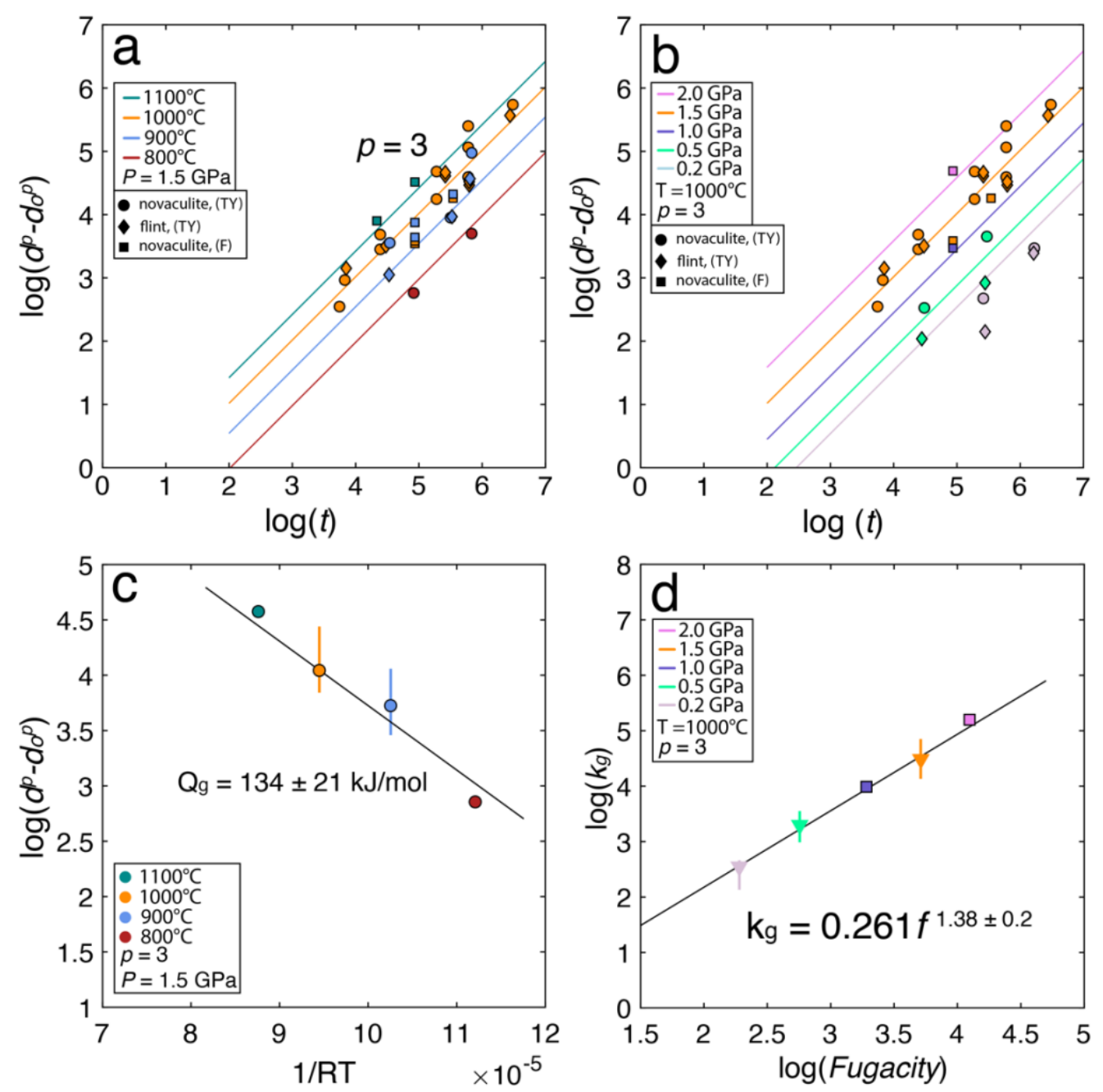

Figure 3. Plots comparing quartz grain growth experiments with our quartz growth grain law. a) Plot of $\log \left(d^{p}-d_{o}^{p}\right)$ versus $\log (t)$ for grain growth experiments at a pressure of $1.5 \mathrm{GPa}$. b) Plot of $\log \left(d^{p}-d_{o}{ }^{p}\right)$ versus $\log (t)$ for grain growth experiments at $\mathrm{T}=1000^{\circ} \mathrm{C}$ and $\mathrm{P}=2.0,1.5$, 1.0, 0.5, and $0.2 \mathrm{GPa}$. c) Plot of $\log \left(d^{p}-d_{o}^{p}\right)$ versus $1 / \mathrm{RT}$. The $\log \left(d^{p}-d_{o^{p}}\right)$ values in part $c$ come from best fits to the data for a given temperature in Figure $\mathrm{S} 4 \mathrm{a}$ at $\log (t)=5.0$. For $900^{\circ} \mathrm{C}$ and $1000^{\circ} \mathrm{C}$, the dot represents the average $\log \left(d^{p}-d_{o}{ }^{p}\right)$ value and the vertical lines represent the spread in the data in Figure S4a. d) Plot of log water fugacity versus log $k_{g}$. The triangles represent the average $\log \mathrm{kg}$ value with the vertical lines representing the spread in the data. Supplementary Figure S5 compares the measured grain size and time data with the grain growth law presented in this figure.

Following these observations, we formulated a new grain growth law for wet quartz.

We reanalyzed the microstructures in the samples from the grain growth experiments conducted by Tullis and Yund (1982). We found that approximately $20 \%$ of the samples used to develop the Wightman et al. (2006) grain growth law exhibited microstructures indicative of either abnormal grain growth (Figure $2 b$ ) or second phase pinning due to the presence of oxides (Figure 2c,d). In our analysis we also include several grain growth experiments conducted by Fukuda et al. (2019) on novaculite. We only include grain growth experiments 
by Fukuda et al. (2019) that were conducted at the same starting water content (1-2 wt\%) as Tullis and Yund (1982). All of the experimental grain growth data used in our analysis are listed in supplementary Table S2. We define our grain growth law for wet quartz by equations 5 and 6 (see Table 1 for symbols and descriptions):

$d^{p}-d_{o}^{p}=K t$

$K=k_{g} e^{\left(\frac{-Q g}{R T}\right)}$

where $k_{g}=A_{g} f_{H_{2} \mathrm{O}}^{r_{g}}$ (e.g., Fukuda et al., 2019). Our analysis gives grain growth parameters: $p$ $=3.0 \pm 0.4, k_{g}=0.261 f^{1.38 \pm 0.3}$, and $Q_{g}=134 \pm 21 \mathrm{~kJ} / \mathrm{mol}$, where uncertainties represent 1 standard deviation (Figure 3). The grain growth exponent $(p)$ is determined by fitting the grain growth experiments conducted at $T=1000^{\circ} \mathrm{C}$ and $P=1.5 \mathrm{GPa} ; p$ is empirically determined when the slope equals 1 for a linear fit of the data on plots of $\log \left(d^{p}-d_{o}^{p}\right)$ versus $\log (t)$ (Figures 3a and S1). Supplementary Figure S3 shows the variation in the slope for values of $p$ from 2 to 4 . To determine $A_{g}, r_{g}$, and $Q_{g}$, we perform a least squares linear regression assuming $p=3$. The resulting parameter values are listed in Table 2. In Figure 3, we plot the derived grain growth law together with the data, showing that the grain growth law provides a good fit to the experimental data over a range of pressure/water fugacity and temperature. We use equation 7 to estimate the water fugacity at crustal conditions, where $a_{\mathrm{H}_{2} \mathrm{O}}$ is the water activity and $A_{1}, A_{2}$, and $A_{3}$ are empirically fit constants. Equation 7 was formulated by Shinevar et al. (2015), who empirically fit the thermodynamic database of Pitzer and Sterner (1994) to determine a single equation that provides a good fit to the fugacity data for a wide range of crustal geotherms and determined $A_{1}=5521 \mathrm{MPa}, A_{2}=$ $31.28 \mathrm{~kJ} / \mathrm{mol}$, and $A_{3}=-2.009 \times 10^{-5} \mathrm{~m}^{3}$. Equation 7 is also used to determine the water fugacity in the flow laws.

$$
f_{\mathrm{H}_{2} \mathrm{O}}=a_{\mathrm{H}_{2} \mathrm{O}} A_{1} \exp \left(-\frac{A_{2}+P A_{3}}{R T}\right)
$$


Table 2. Grain Growth Parameters for Quartz

\begin{tabular}{|c|c|c|c|}
\hline & $p$ & $k_{g}$ & $Q_{g}(\mathrm{~kJ} / \mathrm{mol})$ \\
\hline $\begin{array}{c}\text { Wightmen et al. } \\
(2006)\end{array}$ & 3.2 & $4.96 P^{2.34}$ & 215 \\
\hline $\begin{array}{c}\text { Fukuda et al. } \\
(2019), \text { nov }\end{array}$ & $2.9 \pm 0.4$ & $10^{-5.8} f_{H_{2} O}^{1.9}$ & $60 \pm 49$ \\
\hline This study & $3.0 \pm 0.4$ & $0.261 f_{H_{2} O}^{1.38} \pm 0.2$ & $134 \pm 21$ \\
\hline
\end{tabular}

\section{Discussion}

Motivated by our observations in Figure 1, we assess the utility of the wattmeter model in predicting quartz recrystallized grain sizes and its implications for estimating stress at crustal conditions. First, we discuss the comparison between our reformulated grain growth law and the Wightman et al. (2006) and Fukuda et al. (2019) grain growth laws. Second, we illustrate that the two wattmeters derived using the two quartzite flow laws from Tokle et al. (2019) fit the stress versus grain size data for all water-added experiments. Third, we discuss the effects of temperature and water fugacity dependence on predicting the grain size, and their importance for extrapolating empirically derived laboratory relationships to crustal conditions. Fourth, we provide a few remarks on the activation volume for creep and grain growth. Finally, we discuss the effects of using the RMS or arithmetic mean 2D grain size and its effects on the wattmeter's stress versus grain size relationship and the application of our calibrated wattmeters for predicting paleo-stresses at crustal conditions. 

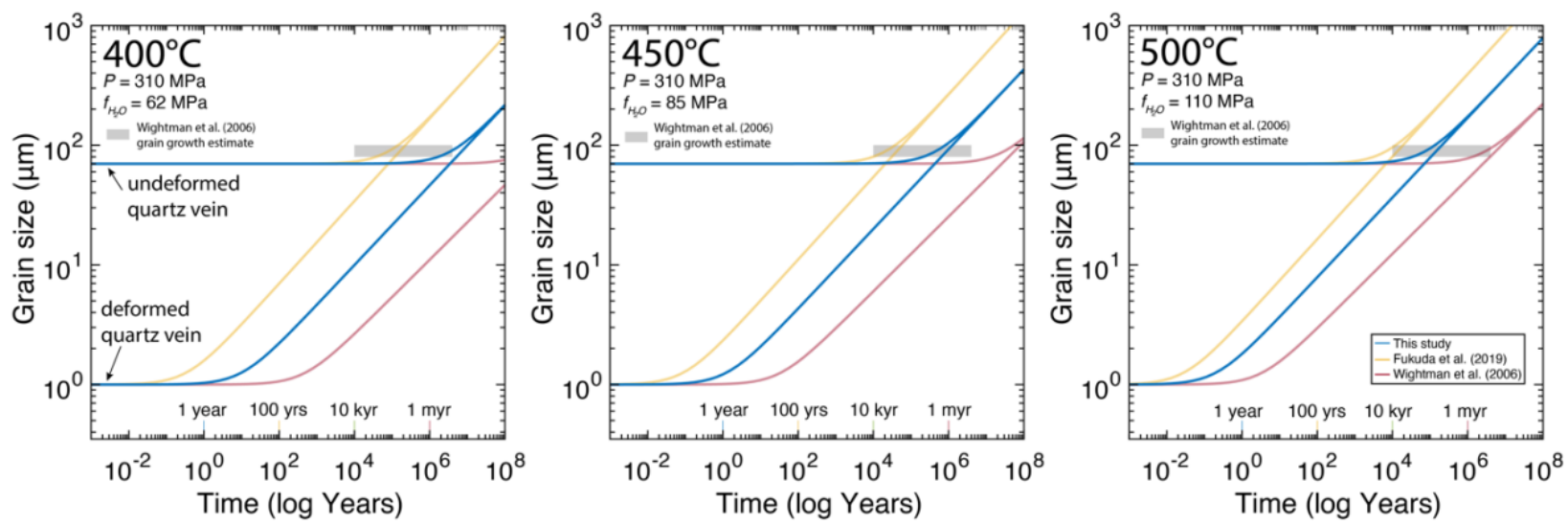

Figure 4. Plots of log grain size versus log time in years comparing our quartz grain growth law with the natural grain growth estimates determined by Wightman et al. (2006). We also compare our grain growth laws with the Wightman et al. (2006) and Fukuda et al. (2019) grain growth laws. There are two starting grain sizes of $1 \mu \mathrm{m}$ and $70 \mu \mathrm{m}$, representing the starting grain size of the deformed and undeformed quartz vein, respectively. The shaded black region represents the natural grain growth estimates by Wightman et al. (2006). Wightman et al. (2006) did not determine a minimum time estimate for grain growth; however, for this figure we set the minimum time estimate to $10 \mathrm{kyr}$. Time abbreviations at the bottom of each figure: yrs - years, kyr - thousand years, myr - million years.

\subsection{Comparison between grain growth laws}

At crustal conditions, our grain growth law is faster than Wightman et al. (2006) and slower than Fukuda et al. (2019) (Figure 4). The grain growth exponent determined in all three studies is the same within error $(p=2.9-3.2)$, however all three studies determine significantly different activation enthalpies, with Wightman et al. (2006) determining $Q_{g}=$ $215 \mathrm{~kJ} / \mathrm{mol}$, Fukuda et al. (2019) determining $Q_{g}=60 \pm 49 \mathrm{~kJ} / \mathrm{mol}$, and our analysis finding $Q_{g}=134 \pm 21 \mathrm{~kJ} / \mathrm{mol}$ (Table 2). Thus, extrapolating all three grain growth laws to crustal conditions shows a large variation in estimated grain growth for a given time (Figure 4). The fact that the Wightman et al. (2006) grain growth law predicts the slowest growth is expected. As previously noted, a significant number of the grain growth experiments used to formulate the grain growth law show microstructural evidence of phase pinning the quartz grain size (Figure 2). Supplementary Figure S6 shows that samples with secondary phases have systematically smaller grain sizes than samples with no secondary phases for a given time. In addition, the high activation enthalpy determined by Wightman et al. (2006) leads to slower growth rates when extrapolated to crustal temperatures. As for the grain growth law determined by Fukuda et al. (2019), the uncertainty in $Q_{g}$ is relatively large. This uncertainty partly reflects that most of their $1000^{\circ} \mathrm{C}$ grain growth experiments show slower grain growth than $900^{\circ} \mathrm{C}$ experiments (see Figure 10 in Fukuda et al., 2019). A similar result was observed in several novaculite samples conducted by Tullis and Yund (1982), where grain growth was 
faster at $900^{\circ} \mathrm{C}$ than $1000^{\circ} \mathrm{C}$ at $1.5 \mathrm{GPa}$ (as seen in Figure 3a, and the overlap in the range of data shown for $900^{\circ} \mathrm{C}$ and $1000^{\circ} \mathrm{C}$ in Figure 3c). With a smaller activation enthalpy, the Fukuda et al. (2019) law leads to more rapid growth rates when extrapolated to crustal temperatures. The larger activation enthalpy (and lower uncertainty) we determined results from analyzing the combined data set for the 1-2 wt. \% water-added samples, which included the $800^{\circ} \mathrm{C}$ data from Tullis and Yund (1982).

Wightman et al. (2006) compared deformed and undeformed quartz veins to estimate grain growth in quartz at crustal conditions. They posit that recrystallized grains with a grain size of $\sim 1 \mu \mathrm{m}$ in a deformed quartz vein grew to $80-100 \mu \mathrm{m}$ in no more than 4 myr at $450 \pm$ $50^{\circ} \mathrm{C}$ under water saturated conditions. The grain size of the undeformed portion of the same quartz vein is also $80-100 \mu \mathrm{m}$. For the grain size of both the deformed and undeformed portions of the vein to be within $80-100 \mu \mathrm{m}$ after the same period of grain growth, the initial grain size in the undeformed region had to be less than $\sim 70 \mu \mathrm{m}$ (Figure 4). Wightman et al. (2006) estimate that grain growth took place over several million years, however, they do not propose a minimum time estimate. At these conditions, the Wightman et al. (2006) grain growth law is too slow; however, both the Fukuda et al. (2019) and our grain growth law show that grain growth from $1 \mu \mathrm{m}$ to $80-100 \mu \mathrm{m}$ can be achieved in less than 4 myr. The Fukuda et al. (2019) grain growth law is significantly faster than our grain growth law. For the grain growth conditions determined by Wightman et al. (2006), the Fukuda et al. (2019) grain growth law predicts grain growth from $1 \mu \mathrm{m}$ to $80 \mu \mathrm{m}$ in $\sim 30 \mathrm{kyr}$ at $450^{\circ} \mathrm{C}$ and $\sim 10 \mathrm{kyr}$ at $500^{\circ} \mathrm{C}$ while our grain growth law predicts a $\sim 650 \mathrm{kyr}$ at $450^{\circ} \mathrm{C}$ and $\sim 100 \mathrm{kyr}$ at $500^{\circ} \mathrm{C}$ (Figure 4).

\subsection{Predicting the recrystallized grain size using the wattmeter}

With our newly formulated grain growth law, the wattmeter accurately predicts the range of recrystallized grain sizes for all of the water-added experimental samples. To determine the efficacy of applying the wattmeter, we first use equation 3 with the known experimental data consisting of stress, strain rate, pressure, and temperature, to predict the steady state grain size. We find that the wattmeter, with a constant value of the combined term $\gamma / \beta \lambda$ in equation 3 , accurately predicts the recrystallized grain size over the entire range of experimental conditions, including the samples deformed in both the axial and general shear geometry at a wide range of temperatures (Figure 5). Assuming $\beta=1$ and $\gamma=1 \mathrm{~J} / \mathrm{m}^{2}$, this fit indicates a constant value of $\lambda=0.015$. The assumption of a constant value of $\beta \approx 1$ (where $\beta$ is the fraction of the total strain rate accommodated by dislocation creep) is supported by the 
observation that the field boundary (de Bresser et al., 1998; 2001) is both roughly parallel to the piezometric relationship and - based on the relatively sluggish rate of diffusion creep in quartz (e.g., Rutter and Brodie, 2004) - plots at an approximately 50 times lower grain size for a given stress (see Figure 1 in Austin and Evans, 2009). This analysis also suggests that $\lambda$ has the same value regardless of the c-axis fabric (Figure 5). Using the Wightman et al. (2006) and the Fukuda et al. (2019) grain growth laws we calculate $\lambda$ values of 0.025 and 0.010 , respectively (Figure 6). The $\lambda$ values determined for all three grain growth laws are considerably smaller than 0.1, which was used by Austin and Evans (2007); however, these three values are of the order of $\lambda$ values determined for olivine (Holtzman et al., 2018) and ice (Behn et al., 2020).

As shown in Figure 7, the wattmeters successfully predict the variation of grain size versus stress relationships for samples that deform by the different dislocation creep flow laws (with their attendant differences in c-axis fabric). For these figures, we substitute the flow law parameters from Tokle et al. (2019) into the steady state grain size form of the wattmeter (equations 3 and 4). The wattmeter calculated with the $n=4$ flow law is nearly identical to the S\&T piezometer at all experimental conditions, with a slope of -1.25 compared to a slope of -1.26 for the S\&T piezometer. The wattmeter for the $n=3$ flow law has a shallower slope of -1.00 and predicts larger grain sizes for a given stress than the $n=4$ wattmeter at stresses larger than $\sim 15 \mathrm{MPa}$ at experimental conditions (Figure 7). Thus, the application of two wattmeters accurately predicts the variation in stress versus grain size data shown in Figure 1. In Figure 7 we also highlight five samples that were deformed at pressures between 1.0 - 1.1 GPa, while the rest of the samples were deformed at pressures between 1.3-1.6 GPa, showing that the difference in prediction for pressures between $\sim 1.0-1.6 \mathrm{GPa}$ is negligible. Stress versus grain size plots comparing the two wattmeters with all of the wateradded data used in this study are shown in supplementary Figures S7 and S8. We also plot the wattmeters calibrated with the Wightman et al. (2006) and Fukuda et al. (2019) grain growth laws and their fit to the experimental data in stress versus grain size space (supplementary Figures S9, S10). The code used to plot the wattmeters in stress versus grain size space is provided in the supplemental material.

We emphasize that our wattmeters are calibrated for dominantly prism $<\mathrm{a}>$ or basal $<\mathrm{a}>\mathrm{c}$-axis fabrics and that natural quartzite mylonites can develop a range of c-axis fabrics based on a mixture of prism $\langle a\rangle$, prism $\langle\mathrm{c}\rangle$, rhomb $\langle\mathrm{a}\rangle$, and basal $\langle\mathrm{a}\rangle$ orientations. When using the wattmeters to estimate stresses for samples that develop intermediate c-axis fabrics, 
we suggest taking the average of the two wattmeters; at crustal conditions, the variation in stress between the two wattmeters is within the uncertainty of the stresses measured from the experimental samples used to calibrate the wattmeters and piezometers. 


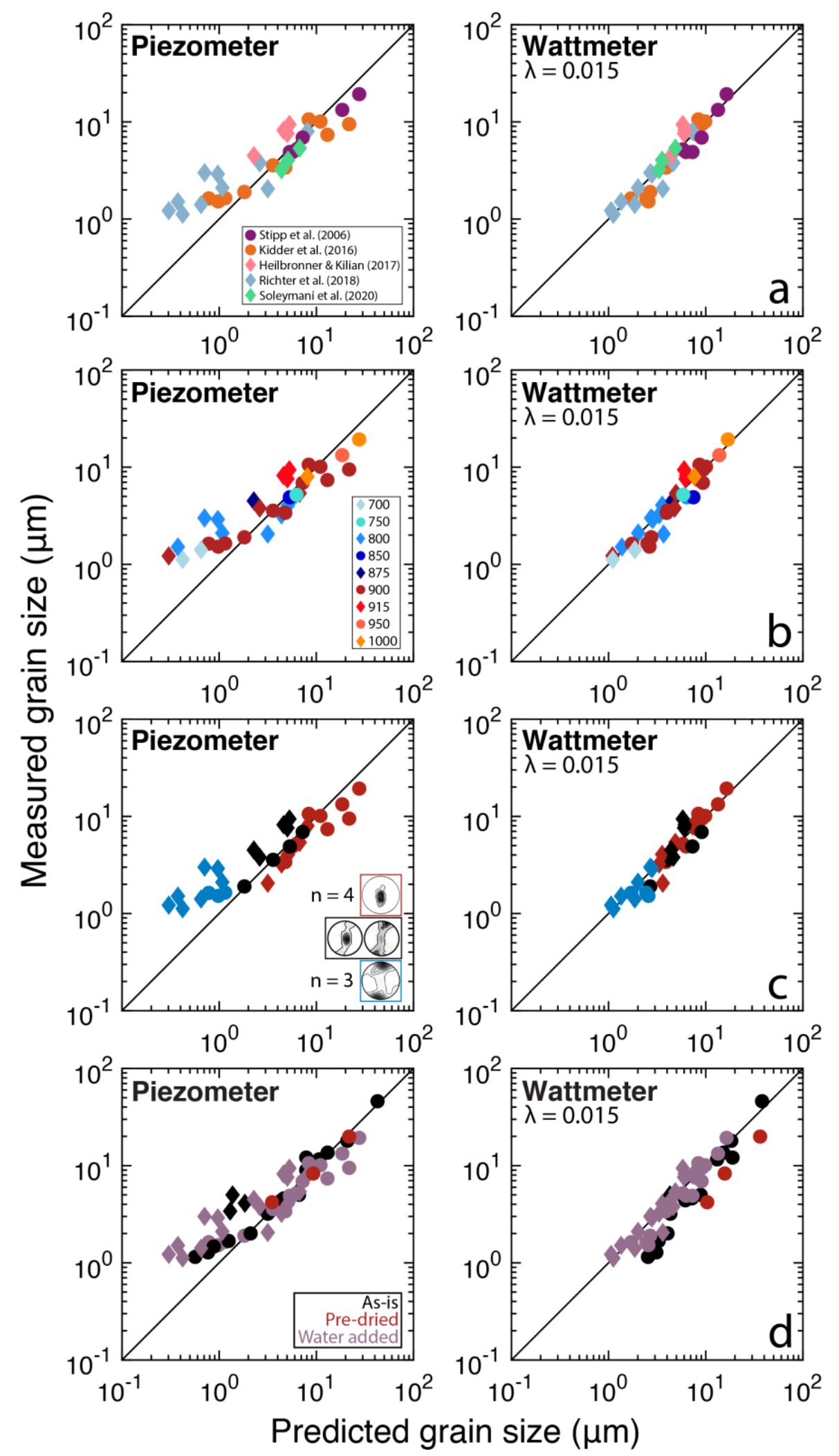

Figure 5. Measured recrystallized grain size versus predicted recrystallized grain size for the Stipp and Tullis (2003) recrystallized grain size piezometer (left column) and wattmeter (right column) by a) study, b) temperature in degrees $\mathrm{C}$, c) c-axis fabric or stress exponent relationship and d) water content. 

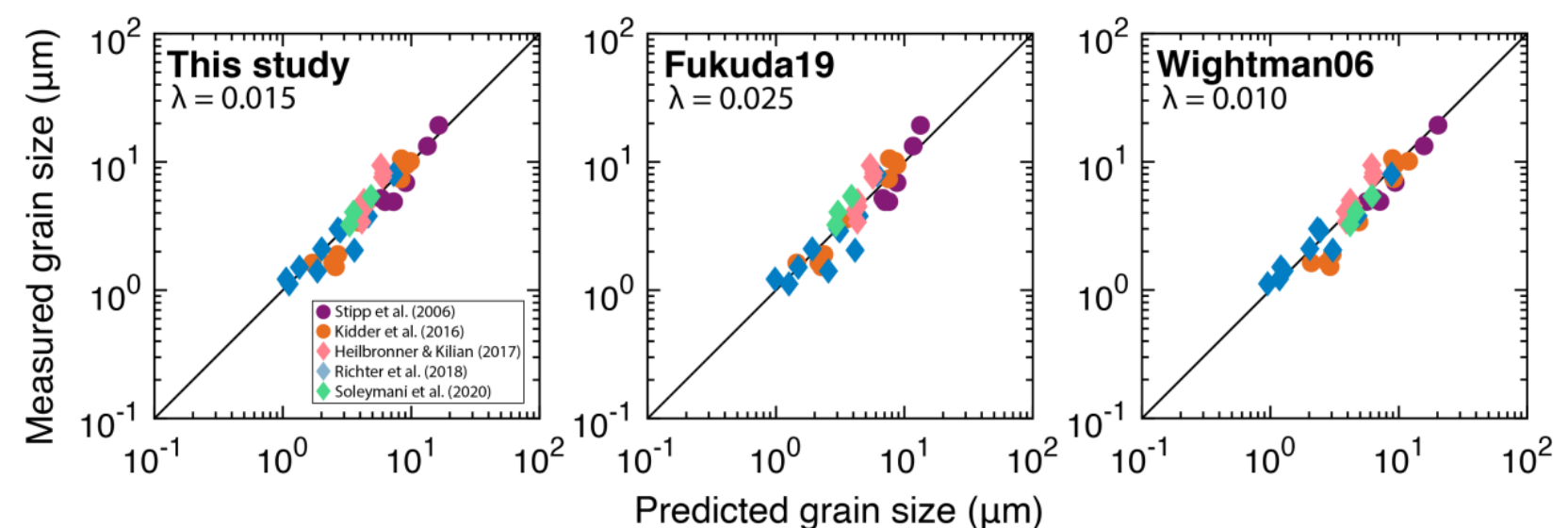

Figure 6. Measured recrystallized grain size versus predicted recrystallized grain size using the same dataset but with different grain growth laws. $\lambda$ is empirically fit in each plot. Fukuda19 and Wightman06 refers to the grain growth laws developed by Fukuda et al. (2019) and Wightman et al. (2006), respectively.
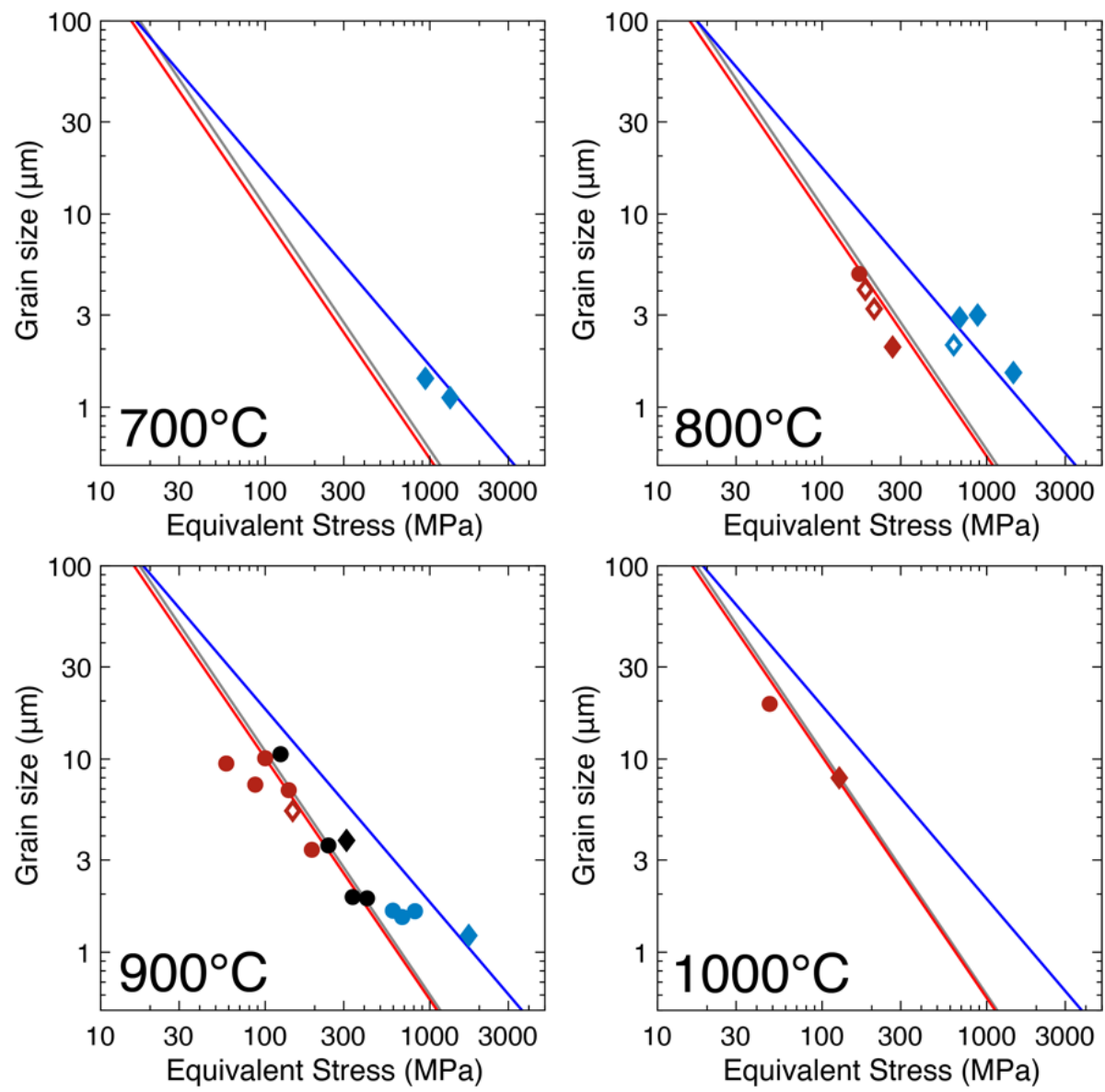

Figure 7. Plots of log grain size versus log equivalent stress comparing the recrystallized grain size versus stress measurements with the $n=4$ and $n=3$ wattmeters using the grain growth law formulated in Figure 3 and the Stipp and Tullis (2003) recrystallized grain size piezometer at $\mathrm{P}=1.5 \mathrm{GPa}$. Samples with white fill were conducted at pressures between 1.0 1.1 GPa. Supplementary Figures S7 and S8 show the comparison between the recrystallized grain size versus stress measurements and the wattmeters at all temperature and pressure conditions. The recrystallized grain size versus stress measurements are color-coded based on Figure 1d. 


\subsection{The influence of temperature and water fugacity}

The wattmeter model provides a prediction for how temperature and water fugacity impact the steady state grain size and grain size evolution of quartz. From equation 4, if $Q_{g}=Q$ and $r_{g}=r$ then no effect of temperature or water fugacity on the stable grain size is predicted. In contrast, if $Q_{g} \neq Q$ or $r_{g} \neq r$ then variations in temperature or water fugacity are predicted to modify the stress versus grain size relationship.

The similar activation enthalpies and water fugacity exponents for both the creep and grain growth laws determined through our analyses suggest only modest effects of temperature and water fugacity on the steady state grain size in quartz. We determined $Q_{g}=$ $134 \pm 21 \mathrm{~kJ} / \mathrm{mol}$ for grain growth, which is within error of the values of $Q=125 \pm 15 \mathrm{~kJ} / \mathrm{mol}$ for the $n=4$ flow law and $Q=115 \pm 15 \mathrm{~kJ} / \mathrm{mol}$ for the $n=3$ flow law determined by Tokle et al. (2019). This assessment is consistent with the experimental results of Stipp and Tullis (2003), who show no resolvable temperature effect on the recrystallized grain size of quartz at their experimental conditions (and by the data in Figure 5b). Nakakoji and Hiraga (2018) and Speciale et al. (2020) show similar results where the activation energies are within error for flow laws and grain growth laws in forsterite +20 vol\% enstatite and wet olivine aggregates, respectively.

Similarly, we determined a water fugacity exponent of $1.38 \pm 0.2$ for grain growth that is similar to the values determined by Tokle et al. (2019), with water fugacity exponents of 1.0 for the $n=4$ flow law and $1.20 \pm 0.2$ for the $n=3$ flow law (errors for the $n=4$ water fugacity exponent are not well-resolved, owing to relatively sparse data). In Figure 5c, we compare our wattmeter model calibrated with water-added samples to data from experiments conducted on as-is and pre-dried samples. The wattmeter accurately predicts the grain size of the as-is samples for grain sizes larger than $2 \mu \mathrm{m}$ (which are all from experiments conducted on Black Hills quartzite); these samples contain a relatively large (but undersaturated) water content (e.g. Stipp et al., 2006). In contrast, the wattmeter overpredicts the grain size of predried samples, suggesting that the influence of water on either the flow laws or the grain growth law changes at very low water contents. The only other outliers, at the smallest grain sizes, are the unpublished results on experiments conducted on as-is novaculite (Bishop, 1996), which have been plotted in previous studies (e.g., Stipp and Tullis, 2003; Kidder et al., 2016). 

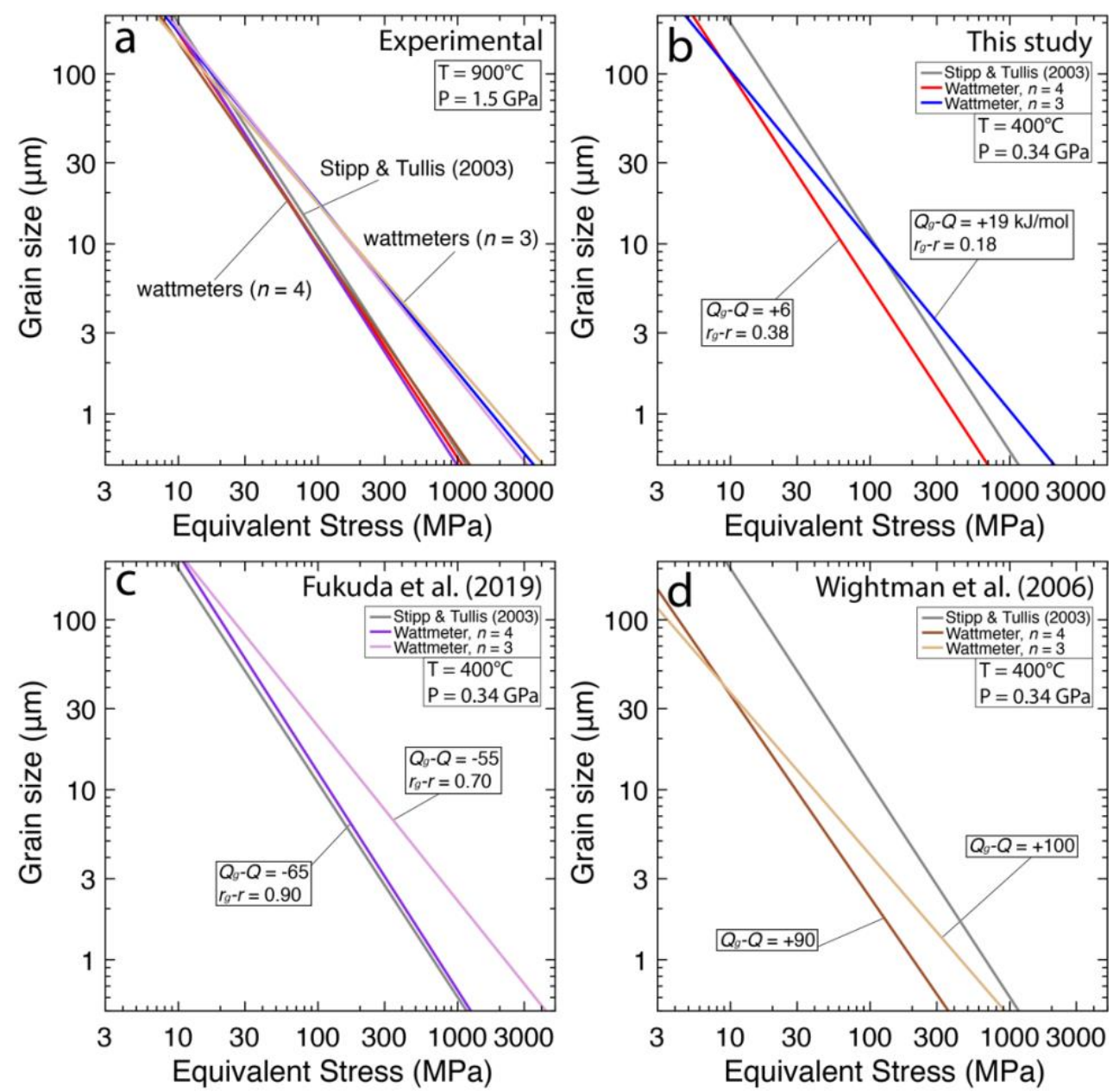

Figure 8. Plots of log grain size versus log equivalent stress comparing the $n=4$ and $n=3$ wattmeter models using the three different grain growth laws presented in Table 2. In plots $b, c, d Q_{g}-Q$ represents the activation enthalpy of grain growth minus the activation enthalpy of creep in $\mathrm{kJ} / \mathrm{mol}$ while $r_{g}-r$ is the water fugacity exponent for grain growth minus the water fugacity exponent for creep. The Stipp and Tullis (2003) piezometer is plotted for reference in all plots. The $\lambda$ values for the corresponding wattmeters are listed in Figure 6.

In Figure 8, we illustrate the effects of temperature (using $Q_{g}-Q$ ) and water fugacity (using $r_{g}-r$ ) on the stress versus grain size relationships at both experimental and crustal conditions. We use the Tokle et al. (2019) flow laws and compare results using the three grain growth laws listed in Table 2. At experimental conditions, $T=900^{\circ} \mathrm{C}$ and $P=1.5 \mathrm{GPa}$, the wattmeters calculated using all three grain growth laws are nearly identical, which is expected because all three grain growth laws and $\lambda$ were constrained at or near this experimental condition (Figure 8a). The wattmeters calibrated with our grain growth law have a $Q_{g}-Q$ less than $20 \mathrm{~kJ} / \mathrm{mol}$ and a $r_{g}-r$ less than 0.40 for both flow laws (Figure $8 \mathrm{~b}$ ). This results in a slight shift in the wattmeters to smaller recrystallized grain sizes for a given stress at crustal conditions (Figure 8b). The wattmeters calibrated with the Fukuda et al. (2019) grain growth law have a large negative value of $Q_{g}-Q$, where $Q_{g}-Q=-65 \mathrm{~kJ} / \mathrm{mol}$ 
(for the $n=4$ flow law) and $Q_{g}-Q=-55 \mathrm{~kJ} / \mathrm{mol}$ (for the $n=3$ flow law). The water fugacity exponent for the Fukuda et al. (2019) grain growth law $\left(r_{g}=2.9\right)$ is also large compared to the values determined for the two flow laws $\left(r_{n=4}=1\right.$ and $\left.r_{n=3}=1.2\right)$, therefore $r_{g}-r=0.90$ for the $n=4$ flow law and $r_{g}-r=0.70$ for the $n=3$ flow law. These differences result in a slight shift in the wattmeters to larger recrystallized grain sizes for a given stress at crustal conditions (Figure 8c). Wightman et al. (2006) calibrated their grain growth law with a pressure-dependent $k_{g}$ (rather than a fugacity term), therefore we only compare the temperature dependence, $Q_{g}-Q$. The activation enthalpy determined by Wightman et al. (2006) $\left(Q_{g}=215 \mathrm{~kJ} / \mathrm{mol}\right)$ is significantly larger than the activation enthalpies determined by the two flow laws $\left(Q_{n=4}=125 \mathrm{~kJ} / \mathrm{mol}\right.$ and $\left.Q_{n=3}=115 \mathrm{~kJ} / \mathrm{mol}\right)$, therefore $Q_{g}-Q=90 \mathrm{~kJ} / \mathrm{mol}$ for the $n=4$ flow law and $Q_{g}-Q=100 \mathrm{~kJ} / \mathrm{mol}$ for the $n=3$ flow law. This results in a large shift in the wattmeters to smaller grain sizes for a given stress at crustal conditions (Figure 8d).

\subsection{A few remarks on the activation volume for quartz rheology}

Recent analyses have highlighted that extrapolation of quartzite flow laws can be impacted by neglecting the activation volume term in the activation enthalpy (Lu and Jiang, 2019). Using a compiled dataset of select experimental samples, Lu and Jiang (2019) calculated a large activation volume $\left(V=35.3 \mathrm{~cm}^{3} / \mathrm{mol}\right)$ for dislocation creep in quartz. Determining $V$ using data from water-added experiments conducted at different confining pressures is difficult because both pressure and water fugacity vary, and there is a co-dependent relationship between $r$ and $V$ (e.g., Karato and Jung, 2003; Hirth and Kohlstedt, 2003). Lu and Jiang (2019) analyze three experiments from Kronenberg and Tullis (1984), and estimate $r=2.7$ and $V=35.3 \mathrm{~cm}^{3} / \mathrm{mol}$. Because $r$ and $V$ are solved simultaneously, uncertainty in $r$ leads to uncertainty in $V$ and vice versa. In contrast, Chernak et al. (2009) concluded that the activation volume could not be too large based on the similarity of the calculated influence of water fugacity determined from experiments conducted with varying fluid composition at constant pressure and temperature and experiments conducted with varying confining pressure at constant temperature (see Figure 16 in Chernak et al., 2009). Pressure-stepping experiments conducted at a constant strain rate, temperature, and fluid content also show agreement between the mechanical results of Kronenberg and Tullis (1984) and Chernak et al. (2009) (Holyoke and Kronenberg, 2013).

An additional complicating factor in the analysis by Lu and Jiang (2019) is that the role of water fugacity has been analyzed using data (the three data points from Kronenberg 
and Tullis, 1984) that follow the two different flow laws determined by Tokle et al. (2019) (see Figure 7a in Tokle et al., 2019). After accounting for this issue, Tokle et al. (2019) determined $r$ values for both flow laws in the range between 1.0 - 1.5 (neglecting the possible role of the activation volume). Based on Figure 5 from Lu and Jiang (2019), the values of $r$ (1.0 - 1.5) determined from experiments that follow the $n=4$ flow law from Tokle et al. (2019) give values of $V$ in the range of $0-12 \mathrm{~cm}^{3} / \mathrm{mol}$, consistent with the assessment of Chernak et al. (2009).

The activation volume for quartz grain growth has not previously been calculated. Using our compiled dataset for grain growth, we performed linear regression fits of equations 5 and 6 assuming a grain growth exponent of $p=3.0$. We determine a low activation volume with a large uncertainty $\left(V_{g}=0.5 \pm 28 \mathrm{~cm}^{3} / \mathrm{mol}\right)$, and a water fugacity exponent $\left(r_{g}=1.4 \pm\right.$ 1.1) with a large uncertainty (Table S3). While this analysis suggests similar activation volumes and water fugacity exponents for the dislocation creep flow laws, to more accurately determine the activation volume and water fugacity exponents will require additional grain growth and deformation experiments focusing on independently determining $r_{g}$ and $V_{g}$.

\subsection{RMS vs. Arithmetic mean calibrated wattmeters}

There are a number of ways to define the 2D grain size (Heilbronner and Barrett, 2013). The S\&T piezometer was calibrated using the RMS grain size; however, the RMS grain size is not always reported in previous work on recrystallized grain sizes in naturally deformed quartzites (Behr and Platt 2011; Kidder et al. 2012; Behr and Platt, 2014 and references therein). The RMS grain size is an upper estimate of the 2D grain size (Cross et al., 2017, Heilbronner and Kilian, 2017, and Richter et al., 2018). Therefore, paleo-stresses may be systematically overestimated by applying the RMS-calibrated S\&T piezometer using data where grain size is reported using the arithmetic or geometric mean. Based on the nine axial compression experiments analyzed by Cross et al. (2017), the difference between the RMS and arithmetic mean grain size measurements has only a minor effect on the piezometric relationship in $\log$ (stress) - $\log$ (grain size) space (Figure 9). However, the 10 general shear experiments analyzed by Richter et al. (2018) show a larger variation between the RMS and arithmetic mean grain size measurements in $\log$ (stress) - $\log$ (grain size) space, while the measurements by Heilbronner and Kilian (2017) lie somewhere in between (Figure 9). A possible explanation for these variations is that the experiments analyzed by Cross et al. (2017) were conducted at lower stresses than the experiments analyzed by Richter et al. 
(2018); however there is still a large difference in the variation in grain size measurements for the lowest stress Richter et al. (2018) experiment, which overlays with several experiments analyzed by Cross et al. (2017) (Figure 9). This suggests that another aspect of the experiments may influence the grain size measurements. Based on the variation in the RMS and arithmetic mean grain sizes in the general shear experiments, as well as the fact that most recrystallized grain sizes in naturally deformed quartzites are not measured using the RMS grain size, we provide wattmeters calibrated for both the RMS and arithmetic mean grain size.

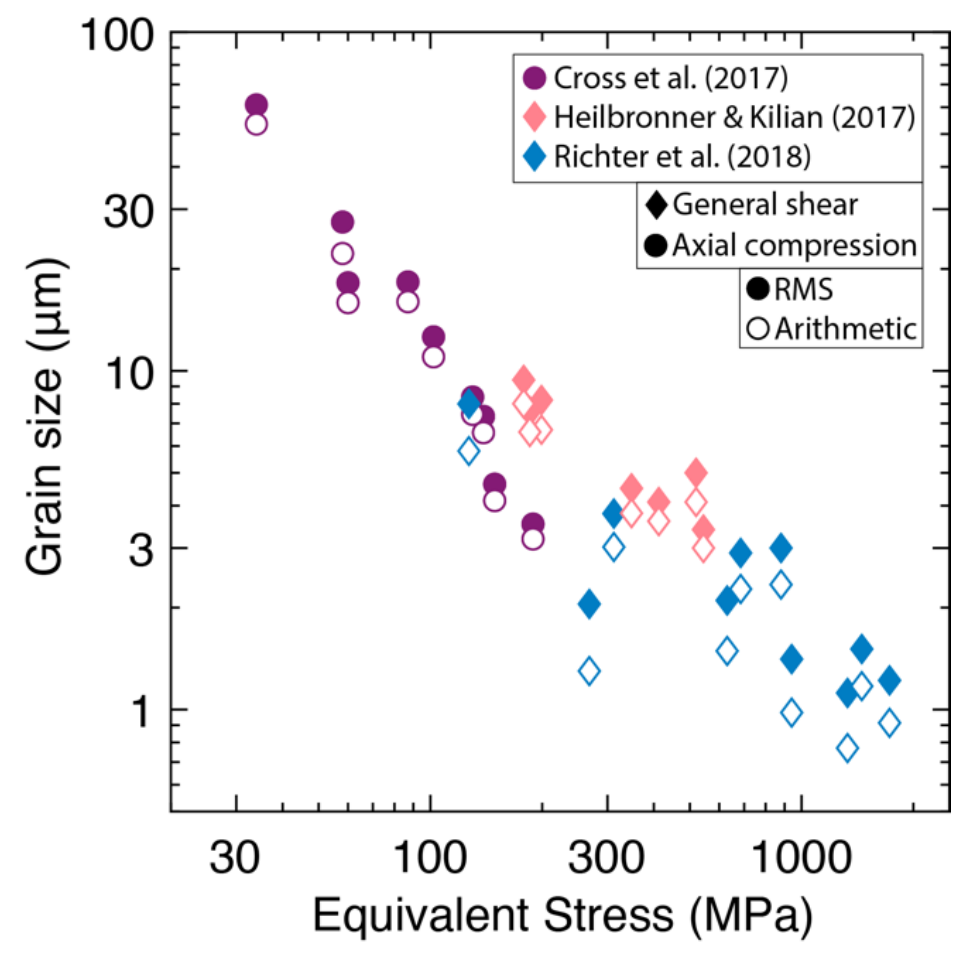

Figure 9. Plot of log stress versus log grain size comparing the RMS and arithmetic mean recrystallized grain size measurements from Cross et al. (2017), Heilbronner and Kilian (2017), and Richter et al. (2018). The Cross et al. (2017) grain size measurements are from the sliding resolution piezometer. All three studies used EBSD to determine grain sizes.

To calibrate the wattmeters for an arithmetic mean grain size, we use 14 experimentally deformed water-added quartz samples for which both a RMS and an arithmetic mean grain size measurement are provided (Cross et al., 2017; Heilbronner and Kilian, 2017; Richter et al., 2018). The value of $\lambda$ is the only parameter that is affected by the grain size measurement technique, with $\lambda=0.015$ for RMS grain size (as shown in Figure 5) and $\lambda=0.04$ for arithmetic mean grain size (Figure 10). The larger value for $\lambda$ results in a minor shift in the two wattmeters, with wattmeters calibrated using the arithmetic mean grain size predicting smaller stresses for a given grain size than the wattmeters calibrated with the 
RMS grain size, consistent with Cross et al. (2017), although the shift in piezometric relationship for the wattmeters is slightly greater than that observed by Cross et al. (2017) (Figure 10c). This difference results from the larger difference in RMS and arithmetic mean grain sizes observed by Heilbronner and Kilian (2017) and Richter et al. (2018).
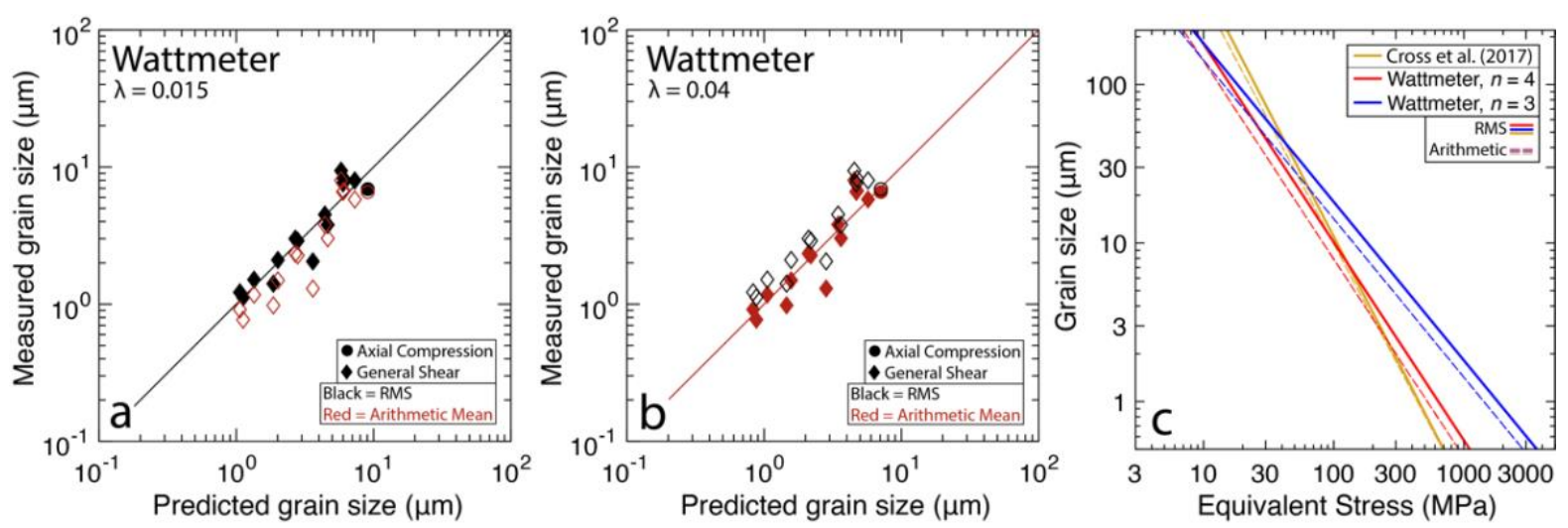

Figure 10. Measured recrystallized grain size versus predicted recrystallized grain size by the wattmeter for samples where the grain size measurement is a) the RMS grain size (black) and b) the arithmetic mean grain size (red). c) Plot of log equivalent stress versus log grain size at $\mathrm{T}=900^{\circ} \mathrm{C}$ and $\mathrm{P}=1.5 \mathrm{GPa}$ comparing the wattmeter models using the $\lambda$ value determined in a) or b) where the solid lines represent the RMS grain size and the dashed lines represent the arithmetic mean grain size. The sliding resolution piezometer developed by Cross et al. (2017) for the RMS and arithmetic mean grain sizes are plotted for comparison.

\section{Implications of the wattmeter}

To illustrate the relationship between the c-axis fabric and the different recrystallized grain size versus stress relationships at crustal conditions, we constructed plots of stress versus depth based on the suite of samples from the Whipple Mountain Core complex (WMCC) analyzed by Behr and Platt (2011), as well as a compilation of data from samples where both the c-axis fabric and recrystallized grain size were measured (Gottardi and Teyssier, 2013; Gottardi et al., 2020; Singleton et al., 2020; Lusk and Platt, 2020). As noted by Tokle et al. (2019), the WMCC samples show a transition in the c-axis fabric from dominantly prism <a> at high temperatures/low stresses to dominantly basal $<\mathrm{a}>$ at low temperatures/high stresses (Figure 11a). The stress versus depth profile calculated using the arithmetic mean-calibrated wattmeters estimates slightly smaller stresses than those predicted by the S\&T piezometer and the Cross et al. (2017) sliding resolution piezometer with a maximum stress of $136 \mathrm{MPa}$ (Figures 11). The stress versus depth plot for the compiled dataset shows a consistent c-axis fabric/stress relationship with depth for the different studies (Figure 12). The samples analyzed by Singleton et al. (2020) estimate the highest stresses in the range of 150-200 MPa 
for a compressional tectonic environment, whereas the highest stresses for an extensional tectonic environment are in the range of 80-140 MPa (Figure 12).
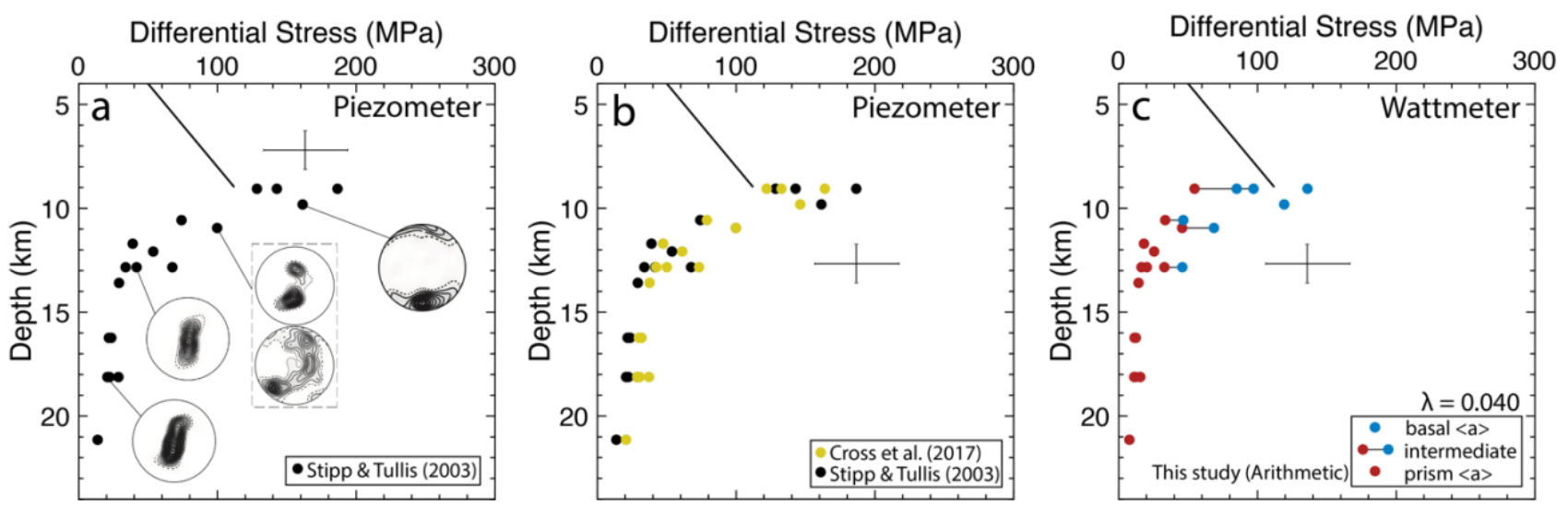

Figure 11. Plots of stress versus depth for the WMCC samples from Behr and Platt (2011) where a) illustrates the relationship of the c-axis fabric in the WMCC samples, b) compares the stress estimated by the Stipp and Tullis (2003) and Cross et al. (2017) sliding resolution recrystallized grain size piezometers, and c) shows the stress determined by the arithmetic mean-calibrated wattmeter. The black lines are the frictional stress assuming a vertical maximum principal stress defined by equation 7a in Zoback and Townend (2001), with $\mu=$ 0.85 and a pore fluid factor of 0.4 following Behr and Platt (2011). The black cross is the representative uncertainty for the stress versus depth measurements. 


\section{Differential Stress (MPa)}

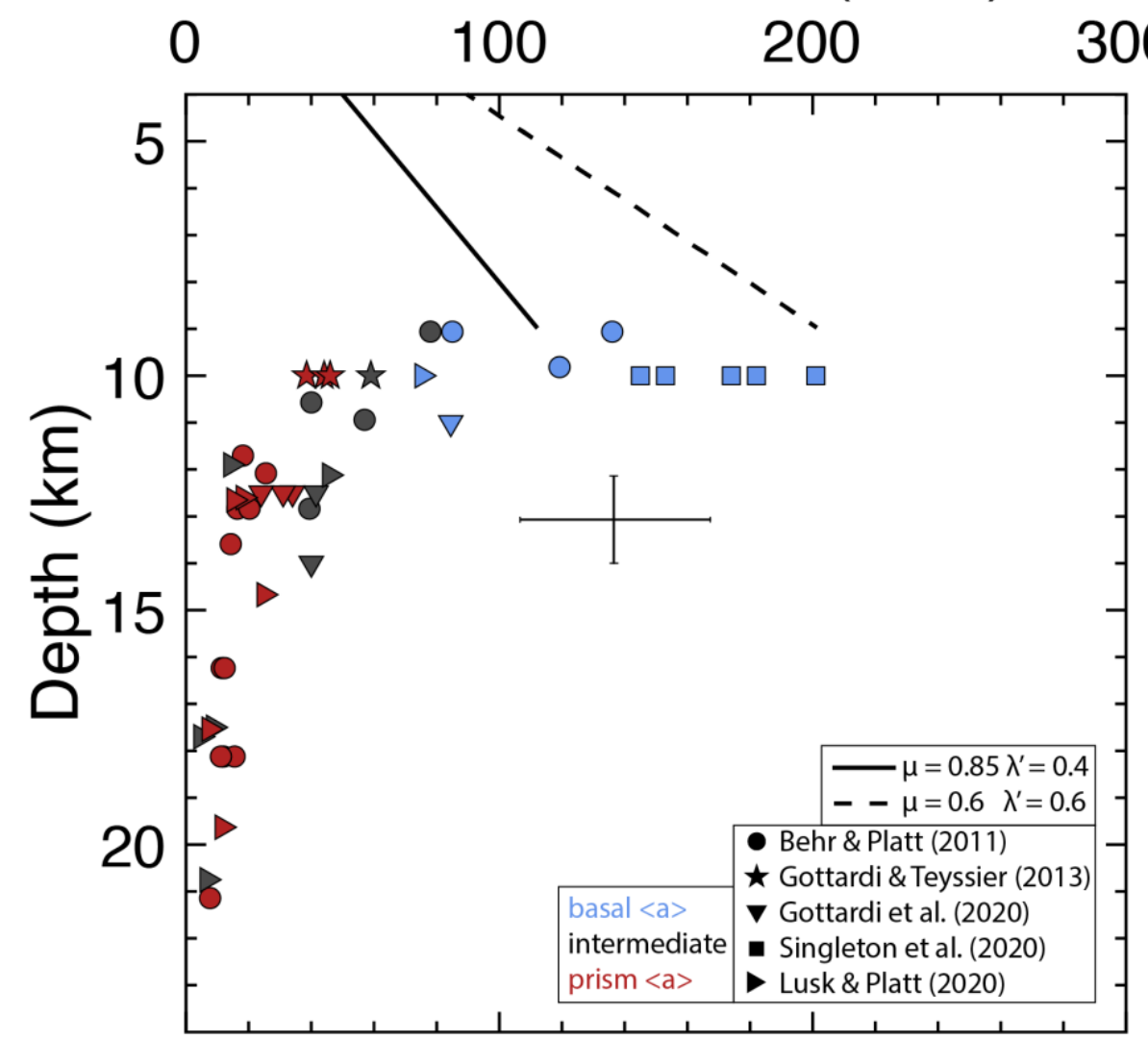

Figure 12. Plot of stress versus depth for the compilation of natural quartzite samples. The solid black line is the frictional stress assuming a vertical maximum principal stress and the dashed black line is the frictional stress assuming a horizontal maximum principal stress defined by equations $7 \mathrm{a}$ and $7 \mathrm{c}$ in Zoback and Townend (2001), respectfully. We define the pore fluid effect for the frictional stress as $\lambda^{c}$. The use of $\lambda^{\natural}=0.6$ for a compressional tectonic environment is consistent with the analysis by Kidder et al. (2012). Samples from Behr and Platt (2011), Gottardi and Teyssier (2013), and Gottardi et al. (2020) are representative of an extensional tectonic environment and Singleton et al. (2020) and Lusk and Platt (2020) are representative of a compressional tectonic environment. The arithmetic mean-calibrated wattmeter was used to estimate stress for the Behr \& Platt (2011) samples while the RMS-calibrated wattmeter was used to estimate stress for Gottardi and Teyssier (2013), Gottardi et al. (2020), Singleton et al. (2020), and Lusk and Platt (2020). The black cross is the representative uncertainty for the stress versus depth measurements.

To illustrate the temperature effect $\left(Q_{g}-Q\right)$ on the stress versus depth estimates of the WMCC samples we compare the wattmeters calibrated using the Wightman et al. (2006) and Fukuda et al. (2019) grain growth laws. The Wightman et al. (2006)-calibrated wattmeters estimate a maximum stress of $46 \mathrm{MPa}$, which results from a large positive $Q_{g}-Q$ value (Figure 13a). In contrast, the wattmeters calibrated with the Fukuda et al. (2019) grain growth law predicts larger stresses, with a maximum stress in excess of $550 \mathrm{MPa}$ (Figure 13b). The variation in the stress versus depth profiles between the Wightman et al. (2006) and Fukuda 
et al. (2019) calibrated wattmeters highlights the sensitivity of extrapolating rheological parameters calibrated at experimental conditions to crustal conditions with over an order of magnitude variation in peak stress estimates based on these two models (Figure 13), even though both sets of calibrated wattmeters accurately predict the experimental data (Figures S8, S9).
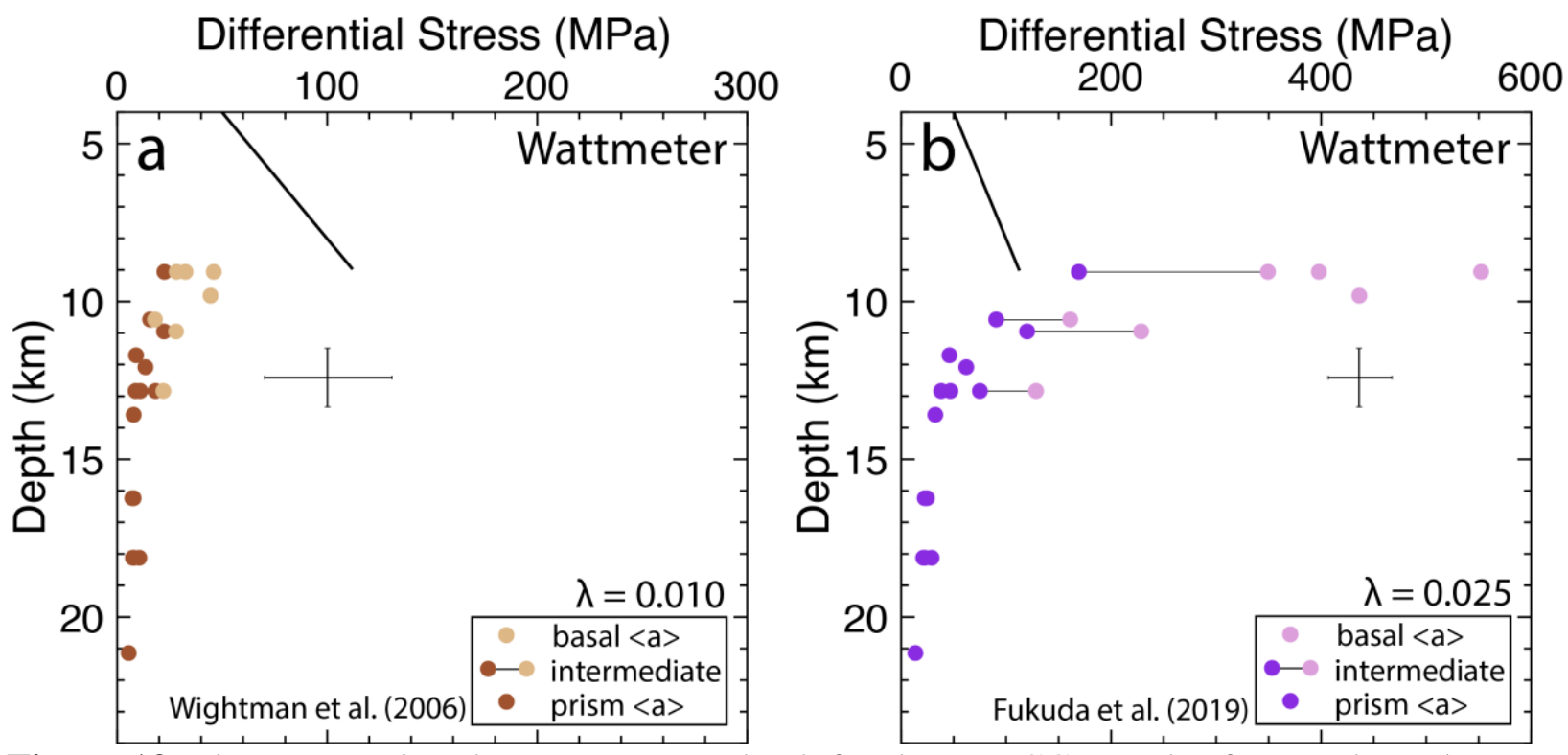

Figure 13. Plots comparing the stress versus depth for the WMCC samples from Behr and Platt (2011) for a) the wattmeter calibrated with the Wightman et al. (2006) grain growth law and b) the wattmeter calibrated with the Fukuda et al. (2019) grain growth law. The black lines are the frictional stress assuming a vertical maximum principal stress defined by equation $7 \mathrm{a}$ in Zoback and Townend (2001), with $\mu=0.85$ and a pore fluid factor of 0.4 following Behr and Platt (2011). The black cross is the representative uncertainty for the stress versus depth measurements.

Previous applications of the wattmeter model to estimate paleo-stresses in quartz at crustal conditions shows that the wattmeter predicts much lower stresses than other independent techniques, such as empirically derived piezometers (Stipp and Tullis, 2003; Cross et al., 2017; Heilbronner and Kilian, 2017), theoretical models (Shimizu et al. 2008), and geodynamic models (Kidder et al. 2012), especially at low temperature/high stress conditions (Kidder et al., 2016; Lu and Jiang, 2019). In contrast, the wattmeters calibrated with the flow laws determined by Tokle et al. (2019) and our reformulated grain growth law provide peak stress estimates for the WMCC that are also consistent with the peak stress estimates from the KTB borehole based on measurements of dislocation density (Dresen et al., 1997) and borehole stress (e.g., Zoback and Townend, 2001). Our wattmeters are also 
consistent with the range of experimental observations (such as the lack of a discernable influence of temperature on recrystallized grain size) and explains the deviation in stress versus grain size relationships for the experimental data (Figure 1).

\section{Conclusions}

The observations of a concomitant switch in the c-axis fabric and stress versus grain size relationship as well as a switch in the c-axis fabric and flow law relationship provides support linking different deformation mechanisms, piezometric relationships, and c-axis fabrics in quartz. By reformulating the quartz grain growth law, we show there is a modest temperature and water fugacity dependence on the stable grain size. Our wattmeter model is able to explain the different stress versus grain size relationships observed at laboratory conditions while also providing stress estimates consistent with other piezometric models. The results of this analysis provide support for the use and extrapolation of the wattmeter model to both experimental and geologic conditions to investigate the stress state and grain size evolution of quartz rich rocks.

\section{Acknowledgements}

This work benefitted from discussions with Jan Tullis, Reid Cooper, Whitney Behr, Cameron Meyers, Seth Kruckenberg, and Andy Cross. We would like to thank David Prior for providing us with the datasets used to develop the grain growth law in Wightman et al. (2006) as well as Steve Kidder for providing several matlab scripts. This research was supported by the National Science Foundation grant EAR-1624178 awarded to G. Hirth. Data used in this study are available through the ETH research collection (URL will be provided once accepted).

\section{Reference}

1. Austin, N., and Evans, B., 2007. Paleowattmeters: A scaling relation for dynamically recrystallized grain size. Geology 35, 343-346, doi:10.1130/G23244A.1.

2. Austin, N., and Evans, B., 2009. The kinetics of microstructural evolution during deformation of calcite. Journal of Geophysical Rearch 114, B09402, doi:10.1029/2008.JB006138.

3. Behn, M., Goldsby, D., and Hirth, G. 2020 in review. The role of grain-size evolution on the rheology of ice: Implications for reconciling laboratory creep data and the Glen flow law. The Cyrosphere Discuss., https://doi.org/10.5194/tc-2020-295.

4. Behr, W.M., and Platt, J.P., 2011. A naturally constrained stress profile through the middle crust in an extensional terrane. Earth and Planetary Science Letters 303, 181 192. doi: 10.1016/j.epsl.2010.11.044. 
5. Behr, W.M., and Platt, J.P., 2014. Brittle faults are weak, yet the ductile middle crust is strong: Implications for lithospheric mechanics. Geophysical Research Letters 41, 8067-8075. Doi:10.1002/2014GL061349.

6. Bishop, R.R., 1996. Grain boundary migration in experimentally deformed quartz aggregates: The relationship between dynamically recrystallized grain size and steady state flow stress, B. Sc. Thesis, 36 pp., Brown Univ., 1996.

7. Cross, A.J., Prior, D.J., Stipp, M., and Kidder, S., 2017. The recrystallized grain size piezometer for quartz: An EBSD-based calibration. Geophysical research letters 44, 6667-6674. doi:10.1002/2017GL073836.

8. Chernak, L.J., Hirth, G., Selverstone, J., and Tullis, J., 2009. Effect of aqueous and carbonic fluids on the dislocation creep strength of quartz. Journal of Geophysical Research, 114, B04201. Doi:10.1029/2008JB005884.

9. de Bresser, J.H.P., Peach, C., Reijs, J., and Spier, C., 1998. On dynamic recrystallization during solid state flow: Effects of stress and temperature. Geophysical Research Letters, vol. 25, p. 3457-3460. Doi: 10.1029/98GL02690.

10. de Bresser, J.H.P., Ter Heege, J.H., and Spiers, C.J., 2001. Grain size reduction by dynamic recrystallization: Can it result in major rheological weakening? International Journal of Earth Sciences, vol. 90, 28-45. https://doi:10.1007/s00530000149.

11. Dresen, G., Duyter, J., Stöckhert, B., Wirth, R., and Zulauf, G., 1997. Quartz dislocation microstructure between $7000 \mathrm{~m}$ and $9100 \mathrm{~m}$ depth from the Continental Deep Drilling Program KTB. J. Geophys. Res., vol. 102, p. 18443-18452. https://doi.org/10.1029/96JB03394.

12. Evans, B., Renner, J., and Hirth, G., 2001. A few remarks on the kinetics of static grain growth in rocks.

13. Fukuda, J., Raimbourg, H., Shimizu, I., Neufeld, K., and Stunitz, H., 2019. Experimental grain growth of quartz aggregates under wet conditions and its application to deformation in nature 10, 621-636. https://doi.org/10.5194/se-10-6212019.

14. Gottardi, R., McAleer, R., Casale, G., Borel, M., Iriondo, A., and Jepson, G., 2020. Exhumation of the Coyote Mountains Metamorphic Core Complex (Arizona): Implications for orogenic collapse of the southern North American Cordillera. Tectonics, 39, e2019TC006050. https://doi.org/10.1029/2019TC006050.

15. Gottardi, R., and Teyssier, C., 2013. Thermomechanics of an extensional shear zone, Raft River metamorphic core complex, NW Utah. Journal of Structural Geology, 53, 54-69. http://dx.doi.org/10.1016/j.jsg.2013.05.012.

16. Heilbronner, R., and Barrett, S., 2013. Image analysis in earth sciences: microstructures and textures of earth materials. Vol. 129. Springer Science \& Business Media. 
17. Heilbronner, R., and Kilian, R., 2017. The grain size(s) of Black Hills Quartzite deformed in the dislocation creep regime. Solid Earth 8, 1071-1093. doi: 10.5194/se8-1071-2017.

18. Heilbronner, R., and Tullis, J., 2002. The effect of static annealing on microstructures and crystallographic preferred orientations of quartzites experimentally deformed in axial compression and shear. In: de Meer, S., Drury, M.R., de Bresser, J.H.P., Pennock, G.M. (Eds.), Deformation Mechanisms, Rheology and Tectonics: Current Status and Future Perspectives. Geol. Soc. (Lond.) Spec. Publ. 200, 191-218. https://doi.org/10.1144/GSL.SP.2001.200.01.12.

19. Heilbronner, R., and Tullis, J., 2006. Evolution of c axis pole figures and grain size during dynamic recrystallization: results from experimentally sheared quartzite. J. Geophys. Res. 111. https://doi.org/10.1029/2005JB004194.

20. Hirth, G., and Kohlstedt, D.L., 2003. Rheology of the mantle wedge, in Inside the Subduction Factory, Geophys. Monogr. Ser., vol. 138, edited by J. Eiler, pp. 83-105, AGU, Washington, D.C.

21. Hirth, G., Teyssier, C., and Dunlap, W.J., 2001. An evaluation of quartzite flow laws based on comparisons between experimentally and naturally deformed rocks. Int. J. Earth Sci. 90, 77-87. https://doi.org/10.1007/s005310000152.

22. Holtzman, B.K., Chrysochoos, A., and Daridon, L., 2018. A thermodynamical framework for analysis of microstructural evolution: Application to olivine rocks at high temperature. Journal of Geophysical Research: Solid Earth 123, 8474-8507. https://doi.org/10.1029/2018JB015613.

23. Holyoke, C.W., and Kronenberg, A.K., 2010. Accurate differential stress measurement using the molten salt cell and solid salt assemblies in the Griggs apparatus with applications to strength, piezometers and rheology. Tectonophysics 494, 18-31. doi:10.1016/j.tecto.2010.08.001.

24. Holyoke, C.W., and Kronenberg, A.K., 2013. Reversible water weakening in quartz. Earth and Planet. Sci. Lett. 374, 185-190. https://doi.org/10.1016/j.eps1/2013.05.039.

25. Karato, S.-I., and Jung, H., 2003. Effects of pressure on high-temperature dislocation creep in olivine. Philosophical Magazine, vol. 83, 401-414. Doi: $10.1080 / 0141861021000025829$.

26. Kidder, S., Hirth, G., Avouac, J.-P., and Behr, W., 2016. The influence of stress history on the grain size and microstructure of experimentally deformed quartzite. Journal of Structural Geology 81, 194-206. doi: 10.1016/j.jsg.2015.12.004.

27. Kidder, S., Avouac, J.-P., and Chan, Y.C., 2012. Constraints from rocks in the Taiwan orogen on crustal stress levels and rheology. J. Geophys. Res. 117, 1-13, B09408. Doi: 10.1029/2012JB009303. 
28. Kronenberg, A.K., and Tullis, J., 1984. Flow strengths of quartz aggregates: grain size and pressure effects due to hydrolytic weakening. J. Geophys. Res., Solid Earth 89, 4281-4297. https://doi.org/10.1029/JB089iB06p04281.

29. Lu, L.X., and Jiang, D., 2019. Quartz flow law revisited: The significance of pressure dependence of the activation enthalpy. Journal of Geophysical Research: Solid Earth 124. https://doi.org/10.1029/2018JB016226.

30. Lusk, A.D.J., and Platt, J.P., 2020. The Deep Structure and rheology of a plate boundary-scale shear zone: constraints from an exhumed Caledonian shear zone, NW Scotland. Lithosphere. https://doi.org/10.2113/2020/8824736.

31. Nakakoji, T., and Hiraga, T., 2018. Diffusion creep and grain growth in forsterite +20 vol\% enstatite aggregates: 2 . Their common diffusional mechanism and its consequence for weak-temperature-dependent viscosity. J. Geophys. Res. Solid Earth, 123 9513-9527. https://doi.org/10.1029/2018JB015819.

32. Olgaard, D.L., and Evans, B., 1986. Effect of second-phase particles on grain growth in calcite. J. Am. Ceram. Soc. 69, 272-277.

33. Olgaard, D.L., and Evans, B., 1988. Grain growth in synthetic marbles with added mica and water. Contrib. Mineral Petrol 100, 246-260.

34. Panozzo Heilbronner, R., and Pauli, C., 1993. Integrated spatial and orientation analysis of quartz c-axes by computer-aided microscopy, J. Struct. Geol. 15, 369-382.

35. Paterson, M.S., and Olgaard, D.L., 2000. Rock deformation tests to large shear strains in torsion. J. Struct. Geol. 22, 1341-1358. https://doi.org/10.1016/S01918141(00)00042-0.

36. Pitzer, K.S., and Sterner, S.M., 1994. Equation of state valid continuously from zero to extreme pressures for $\mathrm{H}_{2} \mathrm{O}$ and $\mathrm{CO}_{2}$. J. Chem. Phys. 101, 3111-3116.

37. Richter, B., Stünitz, H., and Heilbronner, R., 2018. The brittle-to-viscous transition in polycrystalline quartz: An experimental study. Journal of Structural Geology 114, 121. doi: 10.1016/j.jsg.2018.06.005.

38. Rutter, E.H., and Brodie, K.H., 2004. Experimental grain size-sensitive flow of hotpressed Brazilian quartz aggregates. J. Struct. Geol. 26, 2011-2023. https://doi.org/10.1016/j.jsg.2004.04.006.

39. Shimizu, I., 2008. Theories and applicability of grain size piezometers: The role of dynamic recrystallization mechanisms. Journal of Structural Geology, vol. 30, 899917. https://doi.org/10.1016/j.jsg.2008.03.004.

40. Shinevar, W.J., Behn, M.D., and Hirth, G., 2015. Compositional dependence of lower crustal viscosity. Geophysical Research Letters 42, 8333-8340. 
41. Singleton, J.S., Rahl, J.M., and Befus, K.S., 2020. Rheology of a coaxial shear zone in the Virginia Blue Ridge: Wet quartzite dislocation creep at $\sim 250-280^{\circ} \mathrm{C}$. Journal of Structural Geology, v. 140, 104109. https://doi.org/10.1016/j.jsg.2020.104109.

42. Soleymani, H., Kidder, S., Hirth, G., and Garapic, G. 2020. The effect of cooling during deformation on recrystallized grain-size piezometry, Geology, vol. 48. https://doi.org/10.1130/G46972.1.

43. Speciale, P., Behr, W.M., Hirth, G., and Tokle, L., 2020. Rates of olivine grain growth during dynamic recrystallization and post-deformation annealing.

44. Stipp, M., and Tullis, J., 2003. The recrystallized grain size piezometer for quartz. Geophysical Research Letters 30. doi: 10.1029/2003GL018444.

45. Stipp, M., Tullis, J., and Behrens, H., 2006. Effect of water on the dislocation creep microstructure and flow stress of quartz and implications for the recrystallized grain size piezometer. J. Geophys. Res., vol. 111, B04201. Doi: 10.1029/2005JB003852.

46. Tokle, L., Hirth, G, and Behr, W.M., 2019. Flow laws and fabric transitions in wet quartzite. EPSL 505, 152-161.

47. Tullis, J., and Yund, R.A., 1982. Grain growth kinetics of quartz and calcite aggregates. Journal of Geology 90, 301-318.

48. Twiss, R.J., 1977. Theory and applicability of a recrystallized grain size paleopizometer, Pageoph, 115, 227-244, 1977.

49. Wightman, R.H., Prior, D.J., and Little, T.A., 2006. Quartz veins deformed by diffusion creep-accommodated grain boundary sliding during a transient, high strainrate event in the Southern Alps, New Zealand. Journal of Structural Geology 28, $902-$ 918.

50. Zoback, M., and Townend, J., 2001. Implications of hydrostatic pore pressures and high crustal strength for the deformation of intraplate lithosphere. Tectonophysics 336, 19-30. 